\title{
Identification of the novel activity-driven interaction between synaptotagmin 1 and presenilin 1 links calcium, synapse, and amyloid beta
}

Akira Kuzuya ${ }^{1 \dagger}$, Katarzyna M. Zoltowska ${ }^{1 \dagger}$, Kathryn L. Post ${ }^{1}$, Muriel Arimon ${ }^{1}$, Xuejing Li ${ }^{1}$, Sarah Svirsky ${ }^{1}$, Masato Maesako ${ }^{1}$, Alona Muzikansky², Vivek Gautam', Dora Kovacs ${ }^{1}$, Bradley T. Hyman ${ }^{1}$ and Oksana Berezovska ${ }^{1 *}$

\begin{abstract}
Background: Synaptic loss strongly correlates with memory deterioration. Local accumulation of amyloid $\beta$ ( $A \beta$ ) peptide, and neurotoxic A 342 in particular, due to abnormal neuronal activity may underlie synaptic dysfunction, neurodegeneration, and memory impairments. To gain an insight into molecular events underlying neuronal activityregulated $A \beta$ production at the synapse, we explored functional outcomes of the newly discovered calcium-dependent interaction between Alzheimer's disease-associated presenilin 1 (PS1)/ $Y$-secretase and synaptic vesicle proteins.

Results: Mass spectrometry screen of mouse brain lysates identified synaptotagmin 1 (Syt1) as a novel synapse-specific PS1-binding partner that shows $\mathrm{Ca}^{2+}$-dependent PS1 binding profiles in vitro and in vivo. We found that A level, and more critically, conformation of the PS1 and the $A \beta_{42 / 40}$ ratio, are affected by Syt1 overexpression or knockdown, indicating that Syt 1 and its interaction with PS1 might regulate A $\beta$ production at the synapse. Moreover, $\beta$-secretase 1 (BACE1) stability, $\beta$ - and $\gamma$-secretase activity, as well as intracellular compartmentalization of PS1 and BACE1, but not of amyloid precursor protein (APP), nicastrin (Nct), presenilin enhancer 2 (Pen-2), or synaptophysin (Syp) were altered in the absence of Syt1, suggesting a selective effect of Syt1 on PS1 and BACE1 trafficking.

Conclusions: Our findings identify Syt1 as a novel $\mathrm{Ca}^{2+}$-sensitive PS1 modulator that could regulate synaptic A avenues for novel and selective synapse targeting therapeutic strategies.
\end{abstract}

Keywords: Synaptotagmin 1, Presenilin 1, Alzheimer's disease, Beta amyloid

\section{Background}

Presenilin 1 (PS1) constitutes the catalytic site of the $\gamma$ secretase complex $[1,2]$ involved, together with $\beta$ secretase 1 (BACE1) [3], in amyloid precursor protein (APP) processing and amyloid $\beta(A \beta)$ production. Abnormal $A \beta$ production is implicated in the pathogenesis of Alzheimer's disease (AD) - a neurodegenerative disorder characterized by progressive memory deterioration (reviewed in $[4,5])$. Although the exact sequence of

\footnotetext{
* Correspondence: oberezovska@mgh.harvard.edu

Akira Kuzuya and Katarzyna M. Zoltowska are co-first authors.

${ }^{\dagger}$ Equal contributors

${ }^{1}$ MassGeneral Institute for Neurodegenerative Disease, Department of Neurology, Massachusetts General Hospital, Harvard Medical School, Charlestown, MA 02129, USA

Full list of author information is available at the end of the article
}

events occurring in the brain and causing AD is not well understood, it appears that $\mathrm{A} \beta$ accumulation occurs before the onset of cognitive decline $[5,6]$ and that synaptic loss most closely correlates with the memory impairments [7-9]. Moreover, traceable $A \beta$ deposition could already be detected in the default mode network brain regions in cognitively normal adults [10], and experimentally induced synaptic activity was shown to increase $A \beta$ production [11-13], indicating a link between synaptic activity and $A \beta$. Interestingly, the level of $A \beta$ in the brain interstitial fluid is closely linked to synaptic vesicle (SV) exocytosis [14]. These findings suggest that $\mathrm{A} \beta$ can be produced locally at the synapse in an activity-dependent manner. However, molecular events 
and proteins involved in neuronal activity-modulated levels of synaptic $A \beta$ remain largely unknown.

Synaptotagmin 1 (Syt1) is a key molecule regulating synaptic vesicle (SV) exocytosis in a calcium $\left[\mathrm{Ca}^{2+}\right]$-dependent manner $[15,16]$. Syt1 contains two $\mathrm{Ca}^{2+}$-binding domains, $\mathrm{C} 2 \mathrm{~A}$ and $\mathrm{C} 2 \mathrm{~B}$, and is one of the major calcium sensors at the synapse promoting SV exocytosis and neurotransmitter release in response to $\mathrm{Ca}^{2+}$ influx [16-18]. Interestingly, increased intracellular calcium levels also enhance production of $A \beta$ and $A \beta 42$ in particular [19-21], implying that $\mathrm{Ca}^{2+}$ influx may modulate the cleavage of APP by $\beta$ - and $\gamma$-secretases. Still, little is known about the local synaptic effects of neuronal activity and $\mathrm{Ca}^{2+}$ on APP processing.

In the present study, we focused on, and searched for, potential neuronal activity-dependent modulators that can affect $\gamma$-secretase activity. We found that PS1 adopts a pathogenic "closed" conformation within minutes of $\mathrm{Ca}^{2+}$ influx triggered by glutamate or $\mathrm{KCl}$ treatment, suggesting a $\mathrm{Ca}^{2+}$-dependent mechanism. An unbiased proteomics screen of the mouse brain lysates in the presence or absence of $\mathrm{Ca}^{2+}$ identified Syt1 as a novel $\mathrm{Ca}^{2+}$-dependent PS1- interacting protein, showing robust Syt1-PS1 binding in the presence of high $\mathrm{Ca}^{2+}$. Furthermore, we found that Syt1 may regulate $A \beta$ production via different mechanisms. We report that Syt1 modulates the architecture and activity of the PS1 $\gamma$-secretase complex affecting the $A \beta$ species produced, is important for BACE1 maturation and stability, and is involved in trafficking and compartmentalization of BACE1 and PS1. Taken together, these data suggest that Syt1 acts as a novel pre-synaptic calcium-dependent interactor of the PS1/ $\gamma$-secretase that can regulate APP processing and, thus, $A \beta$ production/secretion at the synapse in an activitydependent manner.

\section{Results}

PS1 conformation is dynamically regulated by $\mathrm{Ca}^{2+}$ influx in intact neurons

Neuronal activation is reported to modulate $A \beta$ production and elevate the $A \beta 42 / 40$ ratio $[13,19,21]$. The latter correlates with distinct conformation of the PS1/ $\gamma$ secretase [22-25]. To probe for possible dynamic changes in $\mathrm{PS} 1 / \gamma$-secretase in live cells in response to neuronal stimulation we used our previously developed ratiometric spectral Förster Resonance Energy Transfer (FRET) assay that utilizes GFP-PS1-RFP (G-PS1-R) as a reporter of PS1 conformation (Fig. 1a). As determined previously, the GPS1-R protein can traffic through the secretory pathway to the plasma membrane, shows similar subcellular distribution to that of endogenous PS1, can be incorporated into the $\gamma$-secretase complex, is efficiently endoproteolyzed, and reconstitutes the $\gamma$-secretase enzymatic activity in PS1/2 double knockout mouse embryonic fibroblasts (MEF) [25]. The change in the proximity between RFP and GFP fluorophore-tagged PS1 loop- and NT-domains (FRET efficiency) corresponds to the change in the ratio of RFP (598 nm) to GFP (513 nm) fluorescence intensity (R/ $\mathrm{G}$ ratio). The higher the $\mathrm{R} / \mathrm{G}$ ratio the closer the two domains are, indicating so-called "closed" PS1 conformation.

Primary neurons (12-14 days in vitro [DIV]) were transfected with the G-PS1-R and imaged every $\sim 30$ seconds prior to and after $\mathrm{KCl}$ bath treatment inducing membrane depolarization. We detected a rapid increase in the $\mathrm{R} / \mathrm{G}$ ratio within the first minute of the stimulation, which lasted for at least 30 minutes (Fig. 1b and Additional file 1). This suggests that PS1 has a dynamic structure that responds rapidly to $\mathrm{KCl}$ treatment by changing the NT-loop proximity. To confirm this finding, we used another stimulus, glutamate (Glu) that was applied transiently by puffing it directly onto the imaged neuron. Again, a rapid increase in the R/G ratio was observed, indicating a change in the PS1 conformation. In this case, however, the R/G ratio returned to the baseline within 2 minutes, indicating that PS1 conformation was able to recover when the stimulant diffused (Fig. 1b). No change in the R/G ratio was observed in $\mathrm{H}_{2} \mathrm{O}$-treated neurons or in neurons treated with Glu in the $\mathrm{Ca}^{2+} / \mathrm{Mg}^{2+}$ free media. Additional file 1 shows the GFP and RFP emission intensities and the R/ $G$ ratio in cells expressing GFP-PS1 (negative FRET control), GFP-RFP fusion (positive FRET control) or GFP-PS1-RFP, during 30 minutes recording. No GFP or RFP photobleaching was observed under the settings used. The increased $\mathrm{R} / \mathrm{G}$ ratio after $\mathrm{KCl}$ application reflects increased FRET efficiency and is observed in GPS1-R expressing cells only.

To verify that both treatments increase intracellular calcium load $\left(\left[\mathrm{Ca}^{2+}\right]_{\mathrm{I}}\right)$, sister cultures were preloaded with Oregon Green 488 BAPTA-1 AM and imaged using time-lapse settings. Changes in the $\left[\mathrm{Ca}^{2+}\right]_{\mathrm{I}}$ strongly correlated with the $\mathrm{R} / \mathrm{G}$ ratio (Fig. 1c).

These data reveal the dynamic nature of the PS1/ $\gamma$-secretase and suggest that continuous insult (high intracellular $\mathrm{Ca}^{2+}$ ) maintains PS $1 / \gamma$-secretase in a "closed" conformation, while a transient stressor modulates PS1 reversibly.

Furthermore, after 15 minutes of $\mathrm{KCl}$ treatment we could already detect increased levels of the secreted $\mathrm{A} \beta 40(150.5 \pm 21.63 \%, p=0.0294)$ and $\mathrm{A} \beta 42(168.1 \pm$ $27.24 \%, p=0.0286)$, resulting in an increased $A \beta 42 / 40$ ratio (Fig. 1d) and consistent with the PS1 adopting a "closed" conformation at high intracellular $\mathrm{Ca}^{2+}$.

\section{Synaptotagmin 1 is a novel calcium-dependent PS1-binding partner}

To search for potential $\mathrm{Ca}^{2+}$-dependent modulators of the PS1 $/ \gamma$-secretase at the synapse, we performed an unbiased mass spectrometry (MS) proteomics screen of wild type (wt) mouse brain lysed in $1 \%$ Triton X-100 in 
a

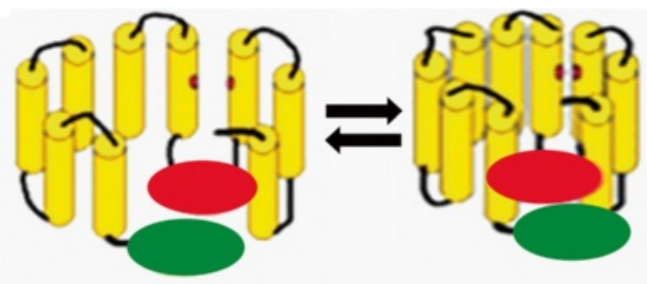

b

PS1 conformation change
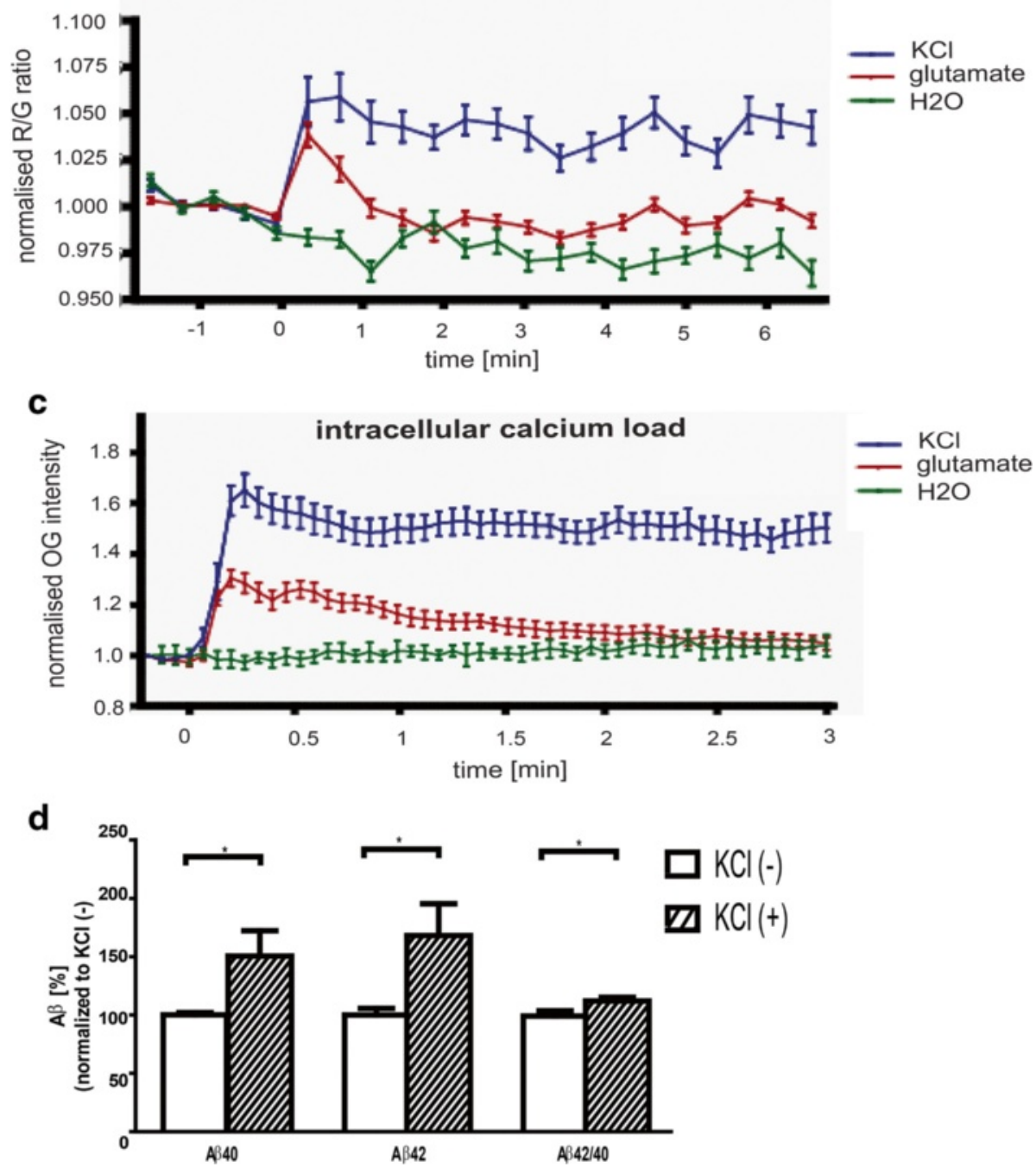

Fig. 1 PS1 conformation and Aß production change upon KCl or glutamate treatment. a Schematic representation of the "open" (left) and "closed" (right) PS1 conformation; green and red circles represent green fluorescent protein (GFP) and red fluorescence protein (RFP) fused to PS1 NT and L6-7, respectively, to generate FRET reporter probe. $\mathbf{b}$ Time-lapse recording of PS1 conformational changes in live neurons transfected with GFP-PS1-RFP FRET reporter probe and treated with $\mathrm{KCl}$, glutamate, or water control. The Spectral FRET data are presented as a change in the RFP/GFP ratio, 50 to 100 neurons were analyzed for each condition; the graph shows mean \pm SEM; detailed statistical analysis of the Spectral FRET data evaluation is described in the Methods. c Time-lapse recording of Oregon Green 488 BAPTA-1 AM fluorescence intensity changes reflecting intracellular calcium load in primary neurons treated with $\mathrm{KCl}$, glutamate, or water control. Three independent experiments, mean \pm SEM. $\mathbf{d}$ ELISA measurements of secreted A 440 and A 42 in conditionedmedium collected from $\mathrm{KCl}(\mathrm{KCl}+)$ or $\mathrm{H}_{2} \mathrm{O}(\mathrm{KCl}-)$ treated mouse cortical neurons. The $\mathrm{A} \beta$ levels determined in pmol were normalized to the amount of total protein [g] extracted from the cells in the corresponding well. Data are presented as mean $\% \pm \mathrm{SEM}, n=4 ; 100 \%=91.11 \mathrm{pmol} / \mathrm{g}$ for $\mathrm{A} \beta 40$ and $11.04 \mathrm{pmol} / \mathrm{g}$ for $\mathrm{A} \beta 42$. Statistical significance was determined using the Mann-Whitney $U$ test, ${ }^{*} p<0.05$. PS1 presenilin $1, A \beta$ amyloid $\beta, N T$ N-terminus, FRET Förster Resonance Energy Transfer 
the presence or absence of $\mathrm{Ca}^{2+}$. Using GST-tagged peptides corresponding to PS1 domains or GST alone as a control, synaptotagmin 1 (Syt1) was identified as a strong candidate for novel PS1-interacting presynaptic protein (Table 1, Fig. 2, and Additional file 2). Syt1 interaction with PS1 was the strongest when GST-fused PS1 L6-7 peptide was used as "bait", although a smaller number of Syt1 peptides was also pulled down with the GST-PS1 NT peptide. Since both L6-7 and PS1 NT sequences used for the pull down are localized within the post-endoproteolytic PS1 $\mathrm{N}$-terminal fragment, the data suggest that Syt1 interacts with the PS1 NTF. Importantly, $\mathrm{Ca}^{2+}$ level affected the interaction between PS1 and Syt1, with robust PS1Syt1 binding observed in the presence of high $\mathrm{Ca}^{2+}$. Identification of known $\mathrm{Ca}^{2+}$-insensitive PS1 interactors, such as catenin delta1, reaffirmed the specificity of the assay for $\mathrm{Ca}^{2+}$-dependent PS1 binding partners.

\section{PS1 co-localizes with Syt1 at presynaptic terminals}

To establish if PS1 co-localizes with Syt1 in the presynaptic terminals, we triple-immunostained synaptoneurosomes (SNSs) isolated from wt mouse cerebral cortex for: 1) PS1, 2) Syt1, and 3) either synapsin 1 (Syn1) and vesicular glutamate transporter 1 (vGlut1) or microtubule-associated protein 2 (MAP2), as preand postsynaptic markers, respectively.

Bright field imaging and immunostaining demonstrate the presence of the snowman-shaped SNSs formed by pre- and post-synaptic terminals (inserts in Fig. 3a) and co-localization of endogenous PS1 with Syt1, Syn1, and vGlut1 at the presynapse, in addition to PS1 presence at the postsynapse (Fig. 3a). Of note, a fraction of the synaptic terminals was PS1 negative in both pre- and post-synaptic compartments. Enrichment of the PS1/ $\gamma$-secretase in the SNSs was further confirmed by western blotting and PS1-colloidal gold immunoelectron microscopy of mouse brain tissue (Fig. 3b and c). The latter showed that PS1 is present in synaptic vesicles of both the reserve and releaseready pools at the presynaptic membrane and within the postsynaptic terminals.

\section{PS1 interacts with Syt1 on endogenous levels}

The use of recombinant GST-PS1 peptide pull-down in the mass spectrometry screen has some limitations due to the possibility of improper folding. Therefore, to verify occurrence of the interaction on endogenous level, we employed a different approach: co-immunoprecipitation (co-IP) of $\mathrm{PS} 1 / \gamma$-secretase with Syt1 using $1 \%$ CHAPSO-solubilized extracts of mouse hippocampi, primary neurons, and cerebral cortex synaptoneurosomes (SNSs). Indeed, Syt1 was co-immunoprecipitated with PS1 (Fig. 4), suggesting a physiological function of the interactions between PS1 and Syt1 in the brain. Of note, other members of the $\gamma$-secretase complex were also pulled down with Syt1 from the $1 \%$ CHAPSO-solubilized extracts, in which interactions among components of the $\gamma$-secretase complex are retained (Fig. 4a).

To validate the $\mathrm{Ca}^{2+}$-dependence of the interactions, SNS fractions were subjected to IP in the presence of $2 \mathrm{mM} \mathrm{CaCl}_{2}\left(\mathrm{Ca}^{2+}+\right)$ or $2 \mathrm{mM}$ EGTA $\left(\mathrm{Ca}^{2+}-\right)$. Indeed, more Syt1 was co-immunoprecipitated with PS1 in the high $\mathrm{Ca}^{2+}$ condition (Fig. 4c). There was no significant effect of $\mathrm{Ca}^{2+}$ on the immunoreactivity of total lysates (input lanes in Fig. 4c) or the efficiency of PS1 NTF and CTF interaction.

To examine which fragment of PS1 (NTF or CTF) predominantly binds Syt1, SNS fractions were lysed in $1 \% \mathrm{Tx}-100$ buffer, disrupting interactions between the $\gamma$-secretase components [26]. The Syt1 band was detected only when anti-PS1 NT antibody was used for the pull-down, suggesting that $\mathrm{Ca}^{2+}$-bound Syt1 selectively interacts with the PS1 N-terminal fragment (Fig. 4d). Since the largest amount of the Syt1 peptides during the MS screen was pulled down with the PS1 peptide corresponding to the amino acids (aa) 263-376 of the L6-7 domain, the region was further narrowed to the aa 263-293, the C-terminal part of the PS1 NTF. Of note, a smaller number of the Syt1 peptides was also detected in the GST-PS1 NT (aa 1-80) pull-down; hence, it is possible that this region provides an additional, lower-affinity interface for the interaction (Fig. 4d).

Table 1 Mass spectrometry screen identified Syt1 as a novel synaptic PS1-binding protein that shows calcium-dependent profile of the interaction

\begin{tabular}{|c|c|c|c|c|c|c|c|c|}
\hline \multirow[t]{2}{*}{ PS1 bait } & \multirow[t]{2}{*}{ Binding protein } & \multirow[t]{2}{*}{ Accession number } & \multirow[t]{2}{*}{ Gene symbol } & \multicolumn{2}{|c|}{ Unique/total peptides } & \multicolumn{2}{|c|}{ Sequence coverage } & \multirow{2}{*}{$\begin{array}{l}\text { Protein function } \\
\mathrm{Ca}^{2+}(+)\end{array}$} \\
\hline & & & & $\overline{\mathrm{Ca}^{2+}(+)}$ & $\mathrm{Ca}^{2+}(-)$ & $\overline{\mathrm{Ca}^{2+}(+)}$ & $\mathrm{Ca}^{2+}(-)$ & \\
\hline NT & Synaptotagmin 1 & NP033332 & SYT1 & $4 / 4$ & None & $11.6 \%$ & None & $\begin{array}{l}\text { Calcium sensor for synaptic vesicle } \\
\text { fusion and neurotransmitter release }\end{array}$ \\
\hline L6-7 & Synaptotagmin 1 & NP033332 & SYT1 & $16 / 26$ & $2 / 2$ & $32.1 \%$ & $5.0 \%$ & \\
\hline L6-7 & Catenin delta 1 & NP031641 & CTNND1 & $17 / 20$ & $25 / 35$ & $20.9 \%$ & $30.8 \%$ & $\begin{array}{l}\text { Known presenilin } 1 \text { interactor in } \\
\text { the brain }\end{array}$ \\
\hline
\end{tabular}

The number of peptides identified and the sequence coverage for Syt1 in $\mathrm{Ca}^{2+}(-)$ and $\mathrm{Ca}^{2+}(+)$ conditions is shown. A known PS1 interacting protein, Catenin1 delta, is shown as $\mathrm{Ca}^{2+}$-independent control 

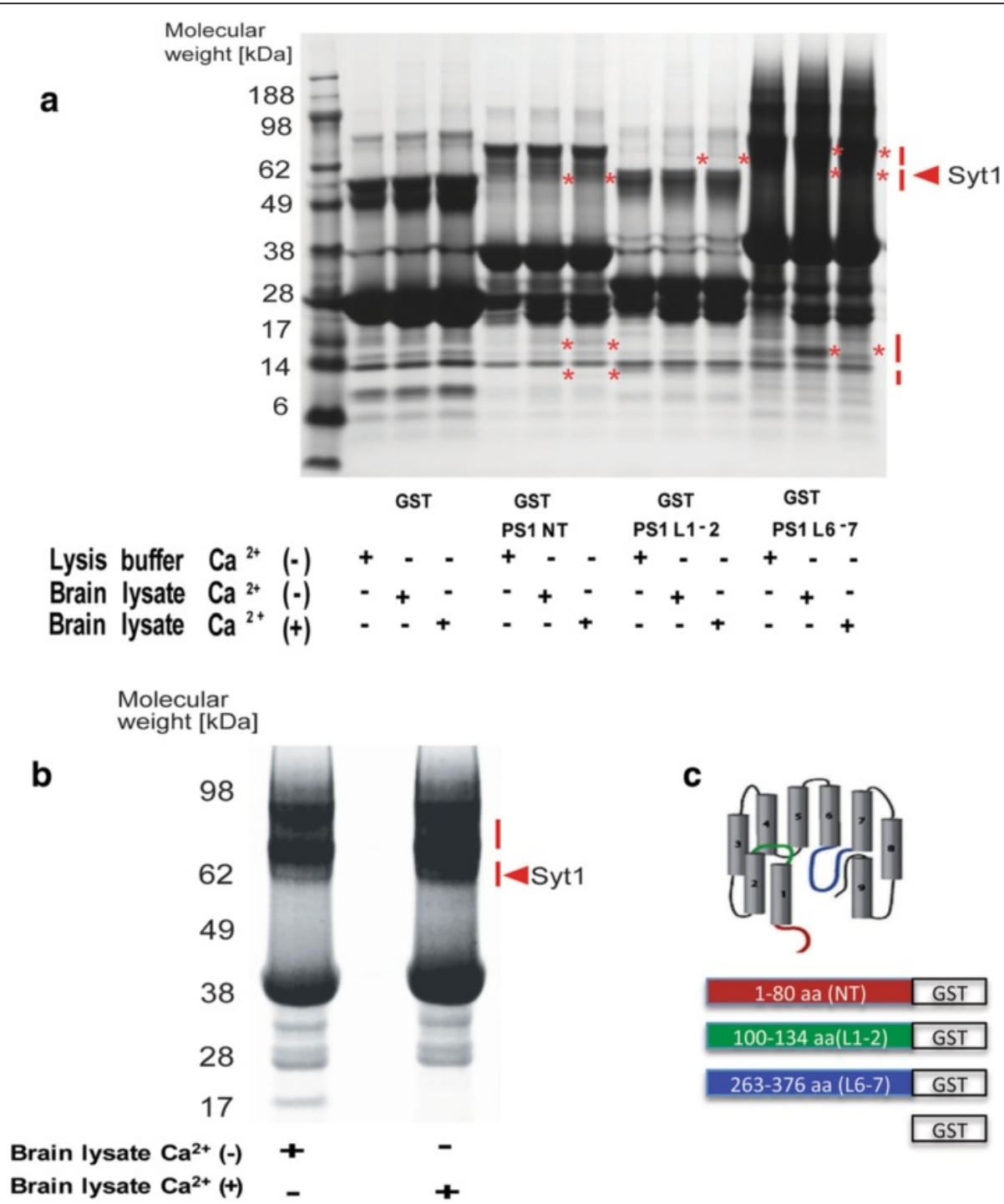

C
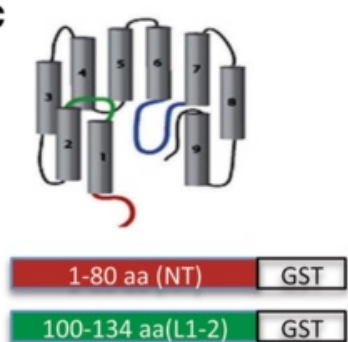

263-376 aa (L6-7) GST

GST

Fig. 2 Mass spectrometry analysis of the PS1 interacting proteins. a Coomassie-stained gel of the proteins eluted from the column. The gel slices with bands of different sizes were excised from the $\mathrm{Ca}^{2+}(+)$ and $\mathrm{Ca}^{2+}(-)$ condition from the GST-PS1 pull-downs, and were sent for mass spectrometry analysis (indicated by lines to the right of the gel). The slice selection was based on the differences in the protein profiles/band intensities between GST-control and GST-PS1 pull-down, GST-PS1 pull-down from brain lysates vs. lysis buffer, and between $\mathrm{Ca}^{2+}(+)$ and $\mathrm{Ca}^{2+}(-)$ condition (these bands are indicated with the asterisks). The bands containing Syt1 are indicated with arrowheads. Three independent MS screens were performed. The Table shows number of peptides identified and the sequence coverage for Syt1 in $\mathrm{Ca}^{2+}(-)$ and $\mathrm{Ca}^{2+}(+)$ conditions; catenin1 delta is shown as $\mathrm{Ca}^{2+}$ independent control. $\mathbf{b}$ Image of the coomassie stained gel from a different MS experiment shows differences in the band intensities for proteins pulled down with the GST-PS1 L6-7 (the area is overexposed in Fig. 2a). The arrowhead points to the band containing Syt1. c Schematic representation of the PS1 molecule and the GST-fusion peptides used in the MS screen of the Triton X-100-digested mouse brain lysates for PS1-binding partners; gray cylinders correspond to PS1 transmembrane domains. PS1 fragments used in the pull-down are labeled in red, green and blue. PS1 presenilin 1, GST glutathione S-transferase, Syt1 synaptotagmin 1, MS mass spectrometry

Next, we tested whether $\mathrm{Ca}^{2+}$ influx into mouse primary neurons due to $\mathrm{KCl}$-induced membrane depolarization or calcium ionophore treatment would enhance endogenous interaction between PS1 and Syt1. For this, 21-28 days in vitro cultured neurons were treated with $\mathrm{KCl}$ or $\mathrm{Ca}^{2+}$ ionophore (A23187) and subjected to co-IP/western blotting. An increased level of Syt1 co-immunoprecipitated with
PS1 in the KCl-stimulated neurons $(134.34 \pm 3.14 \%, p=$ 0.0004), compared to those treated with vehicle (Fig. 5a). An even higher increase was detected when a stronger stimulant, $\mathrm{Ca}^{2+}$ ionophore, was used $(208.6 \pm 22.78 \%, p=$ 0.0089 ). Collectively, these data provide strong evidence for endogenous, activity- and $\mathrm{Ca}^{2+}$ influx-regulated PS1Syt1 interactions in neurons. 
a

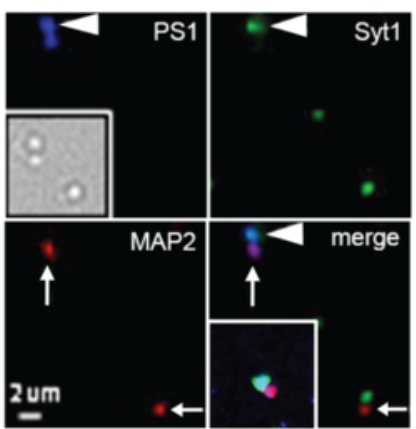

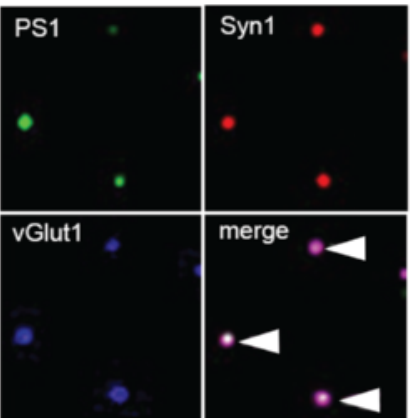

\section{b}
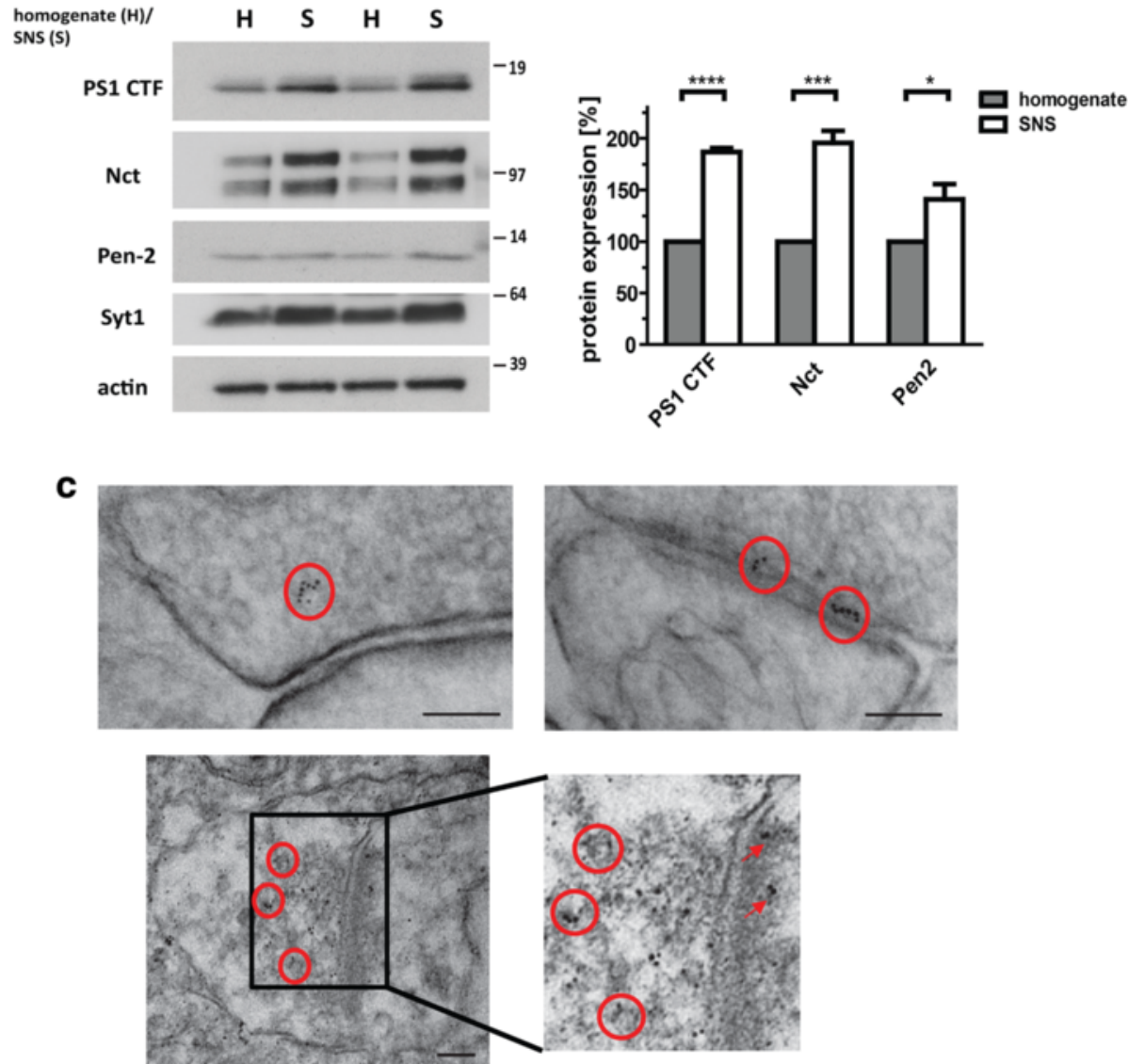

Fig. 3 PS1/Y-secretase present in the pre- and post-synaptic terminals. a Confocal microscopy imaging shows co-localization of PS1 with Syt1 (left) and with synapsin1 and vGlut1 (right) in presynaptic compartments of isolated synaptoneurosomes (SNSs, arrowheads). Arrows show MAP2-positive post-synaptic buttons. Insert on the left shows a bright field image of isolated SNS. b Western blot analysis of PS1 CTF, Nct, Pen-2, Syt1 and $\beta$ actin as a control in total homogenate $(\mathrm{H})$ and synaptoneurosome $(\mathrm{S})$ fractions from wild type mouse brain. Enrichment of the $\gamma$-secretase components in SNS vs. total brain homogenate is quantified. Data are presented as mean $\pm \mathrm{SEM}, n=4$. Statistical significance was determined using the unpaired student $t$-test; ${ }^{*} p<0.05,{ }^{* * *} p<0.001$. c Electron micrographs of synaptic terminals from mouse cortex immunostained for PS1 (gold particles). Red circles and arrows indicate positive staining in presynaptic and postsynaptic compartments, respectively. PS1 presenilin 1, Syt1 synaptotagmin 1, vGlut1 vesicular glutamate transporter 1, MAP2 microtubule-associated protein 2, CTF C-terminal fragment, Nct nicastrin, Pen-2 presenilin enhancer 2

\section{Syt1-PS1 interaction in intact neurons is stimulated by} $\mathrm{KCl}$ treatment

To further validate and characterize endogenous PS1-Syt1 interactions in intact neurons, we employed an antibodybased fluorescence lifetime imaging microscopy (FLIM) analysis. The FRET efficiency (\% $\left.\mathrm{E}_{\mathrm{FRET}}\right)$, reflecting relative proximity between the fluorophore-labeled PS1 L6-7 epitope and Syt1, was increased in neurons stimulated with $\mathrm{KCl}$, compared to vehicle-treated, suggesting more PS1Syt1 interactions in the former (Fig. 5b). 
a

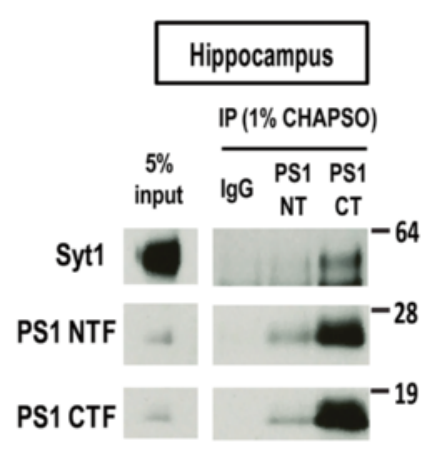

C

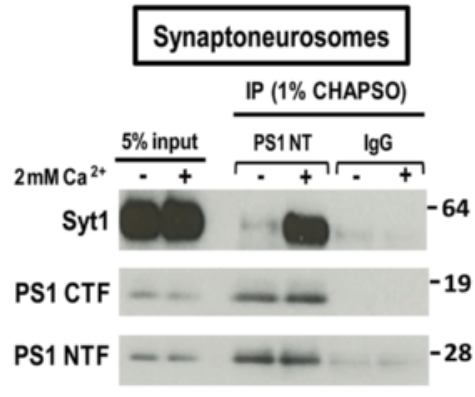

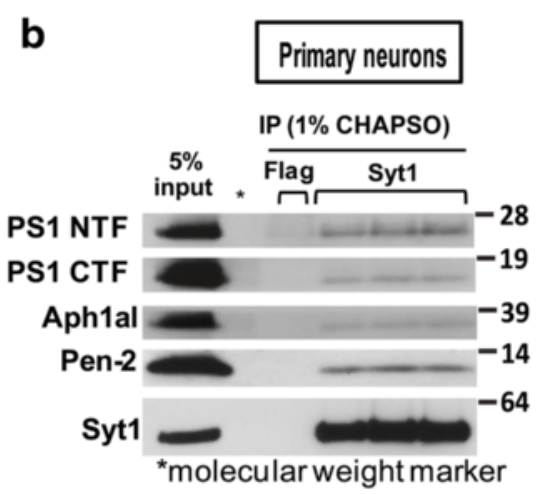
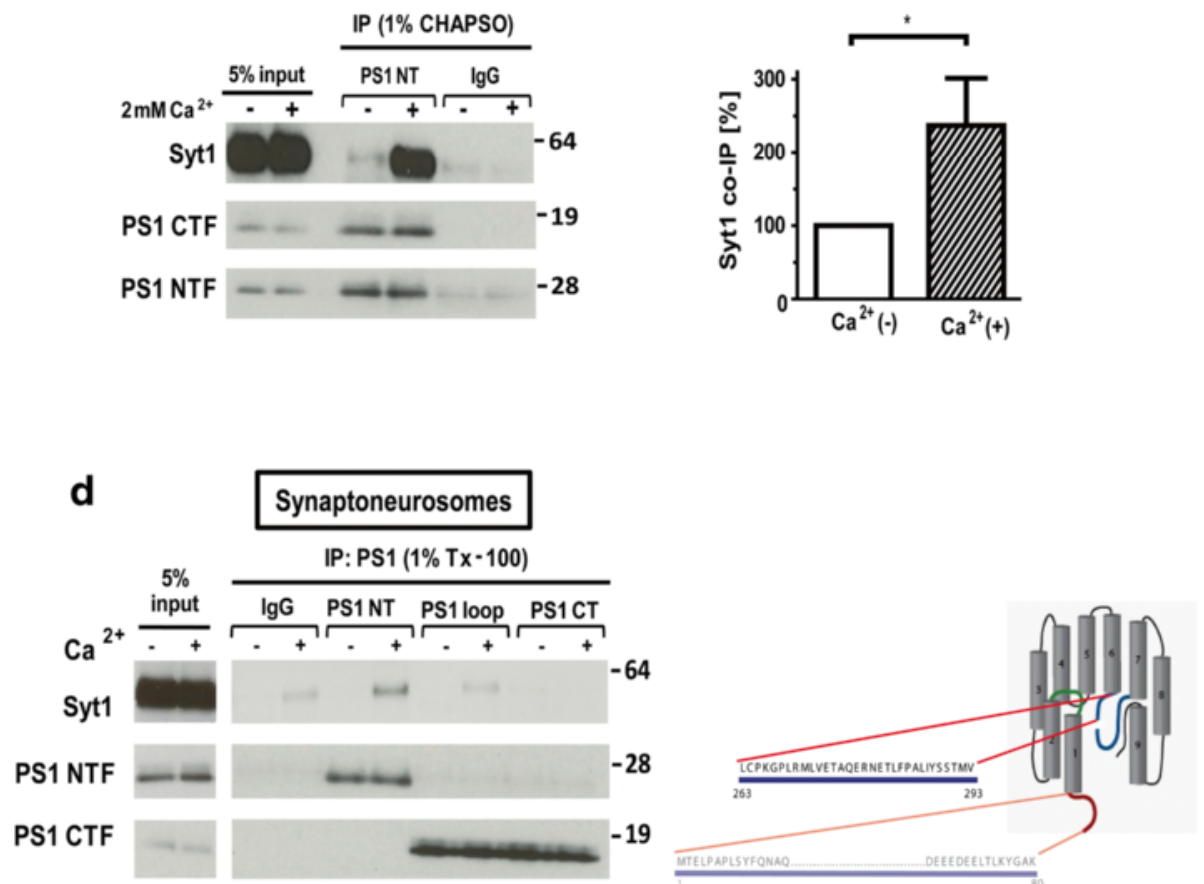

Fig. 4 PS1 interacts with Syt1 on endogenous level. a Syt1 co-immunoprecipitates with PS1 from mouse hippocampi. The co-IP assay was conducted using anti-PS1 CT and anti-PS1 NT antibodies for pull-down; the detection antibodies are indicated to the left of each blot, $n=3$. b PS1 co-immunoprecipitates with Syt1 from mouse cortical primary neurons. The co-IP assay was conducted using anti-Syt1 antibody for pull-down; the detection antibodies are indicated to the left of the blot. Other $\gamma$-secretase components pulled-down with Syt 1 in the $1 \%$ CHAPSO buffer are shown, $n=4$. c Syt1 co-immunoprecipitates with PS1 from synaptoneurosome (SNS) fractions in a $\mathrm{Ca}^{2+}$-dependent manner. SNS were solubilized in $1 \%$ CHAPSO buffer in the presence or absence of $2 \mathrm{mM} \mathrm{CaCl}$. N-terminal PS1 antibody (or lgG control) were used for pull-co-immunoprecipitated with PS1 NTF (normalized to the respective PS1 NTF band intensities). All the data are presented as mean \pm SEM, $n=4$. Statistical significance was determined using the unpaired student $t$-test, ${ }^{*} p<0.05$. $\mathbf{d}$ Syt 1 co-immunoprecipitates with PS 1 from mouse SNSs solubilized in $1 \%$ TritonX-100 buffer in the presence of $2 \mathrm{mM} \mathrm{CaCl}_{2}$ when anti-PS1 NT, but not anti-PS1 loop or anti-PS1 CT antibody, is used for pull-down. The detection antibodies are indicated on the left side of the blot. Schematic representation of the PS1 molecule; the presumed Syt1 interaction sites are shown. PS1 presenilin 1, Syt1 synaptotagmin 1, IP immunoprecipitation, CT C-terminus, NT N-terminus, NTF $\mathrm{N}$-terminal fragment

To determine subcellular localization of the PS1 and Syt1 interactions, donor lifetime was color-coded and mapped on a pixel-by-pixel basis through the entire image. Shortest lifetimes (yellow-to-red pixels) were recorded mainly along the processes and co-localized with the dotted pattern of Syt1 immunoreactivity, presenting synaptic boutons as sites of the $\mathrm{KCl}$-induced PS1-Syt1 interaction (Fig. 5b). Of note, $\mathrm{KCl}$ treatment resulted in a significant increase in the $\% \mathrm{E}_{\mathrm{FRET}}$ along the processes, without having a considerable effect on PS1-Syt1 interactions in the cell bodies. These findings reaffirm that PS1 and Syt1 interaction occurs on endogenous level, and that 


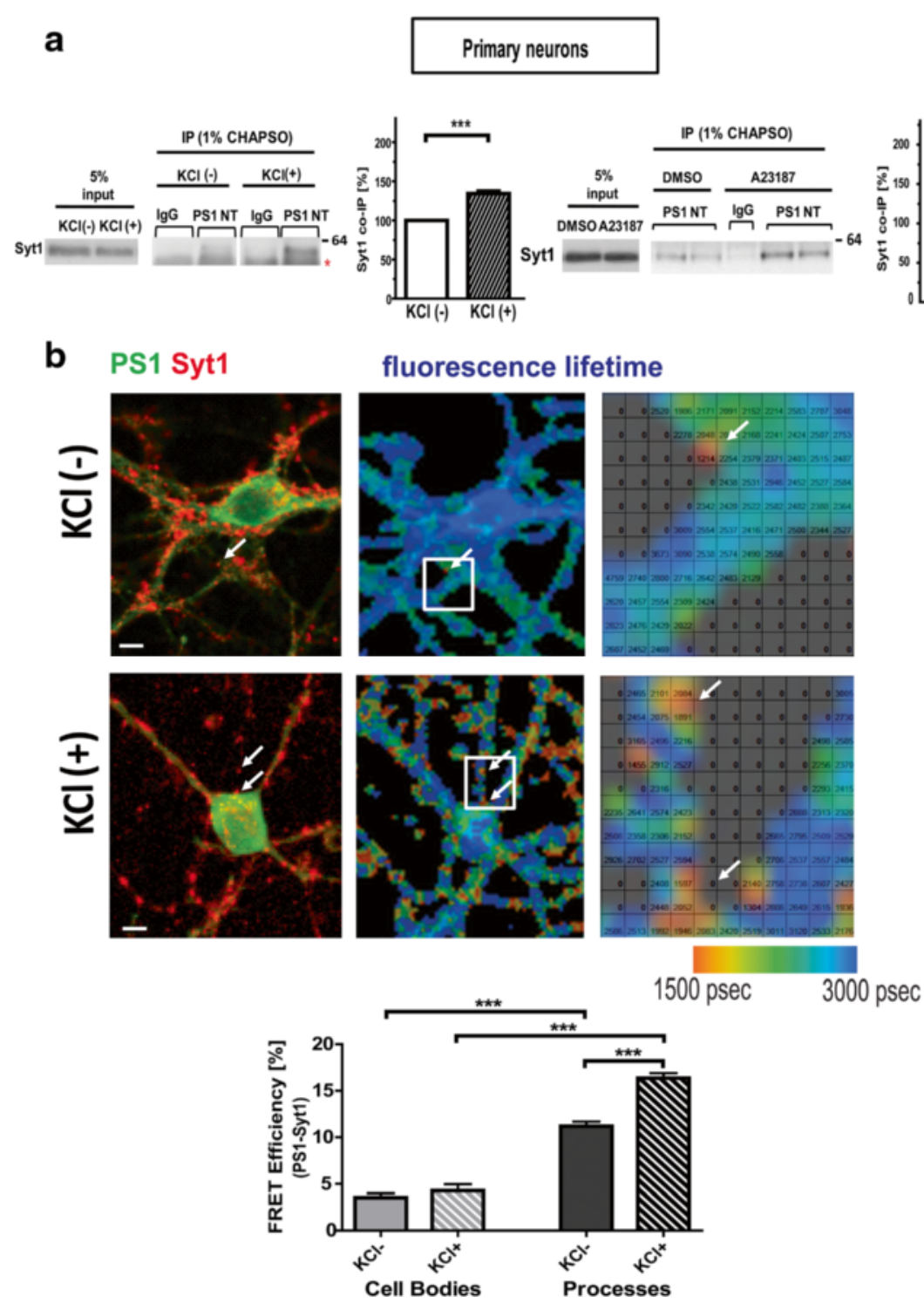

Fig. 5 PS1 interacts with Syt1 in $\mathrm{Ca}^{2+}$-dependent manner in primary neurons. a Co-immunoprecipitation experiments demonstrate that $\mathrm{KCl}(n=3)$ or calcium ionophore A23187 treatment $(n=3)$ of primary neurons that trigger $\mathrm{Ca}^{2+}$ influx strengthen the interaction between PS1 and Syt1. The asterisk shows a non-specific, heavy chain lgG band. The graph presents quantitative analysis of the Syt1 band intensity, mean \pm SEM. Statistical significance was determined using the unpaired student $t$-test, ${ }^{* *} p<0.01,{ }^{* * *} p<0.001$. b FLIM analysis of the PS1-Syt1 proximity in mouse cortical primary neurons treated for 5 minutes with $50 \mathrm{mM} \mathrm{KCl} \mathrm{(KCl+)} \mathrm{or} \mathrm{water} \mathrm{control} \mathrm{(KCl-).} \mathrm{Fluorescence} \mathrm{images} \mathrm{show} \mathrm{PS1} \mathrm{(green)} \mathrm{and} \mathrm{Syt1} \mathrm{(red)} \mathrm{immunoreactivity.} \mathrm{Scale} \mathrm{bar:}$ $5 \mu \mathrm{m}$. Pseudo-colored FLIM images depict lifetime of the Alexa 488 donor fluorophore. Colorimetric scale shows fluorescence lifetime in picoseconds. Zoomed boxed area shows FLIM image superimposed onto a table indicating average lifetimes for each pixel $\left(\sim 0.2\right.$ um $\left.^{2}\right)$ of the image. Shortest lifetimes (yellow-to-red) reflect closest proximity between PS1 and Syt1. Bar graph presents [\%] FRET efficiency (PS1-Syt1 proximity) recorded in the outlined regions of interest (ROIs) corresponding to the neuronal cell bodies or the processes. (mean $\pm \mathrm{SEM} ; n=82$ for cell bodies $\mathrm{KCl}(-), n=63$ for cell bodies $\mathrm{KCl}(+), n=128$ for processes $\mathrm{KCl}(-)$ and $n=146$ for processes $\mathrm{KCl}(+)$; unpaired student $t$-test, $\left.{ }^{* * *} p<0.001\right)$. PS1 presenilin 1, Syt1 synaptotagmin 1, FLIM fluorescence lifetime imaging microscopy, FRET Förster Resonance Energy Transfer

$\mathrm{Ca}^{2+}$-influx induces the interaction primarily at the Syt1positive loci along the dendrites in primary neurons.

\section{Syt1 3D-A mutations impair $\mathrm{Ca}^{2+}$-dependent interactions} between PS1 and Syt1

To gain further insight into the $\mathrm{Ca}^{2+}$-dependency of the Syt1 interaction with PS1, we constructed a 3D-A Syt1 mutant by substituting for alanine three aspartate residues important for $\mathrm{Ca}^{2+}$ binding [27]. PC12 cells lacking Syt1 (Syt1 KD) were transfected with wild type or 3D-A Syt1-V5 plasmids, treated with $\mathrm{KCl}$ or vehicle, harvested, and subjected to co-IP/western blotting. As expected, significantly enhanced interaction of wt Syt1-V5 with PS1 was observed in response to $\mathrm{KCl}$. In contrast, 3D-A 
Syt1-V5 binding to PS1 was significantly reduced compared to that of wt Syt1 in KCl-treated cells (Fig. 6a, c). Analogously, the interaction between mutant 3D-A Syt1-V5 and PS1 in $\mathrm{Ca}^{2+}$ ionophore-treated Chinese hamster ovary $(\mathrm{CHO})$ cells was significantly weaker compared to that of wt Syt1-V5 and PS1 (Fig. 6b, c). These results support the importance of $\mathrm{Ca}^{2+}$ binding to Syt1 in the regulation of the PS1-Syt1 interactions.

\section{Syt1 affects endogenous $A \beta$ production and PS1 conformation}

The above data provide strong evidence that $\mathrm{Ca}^{2+}$ influx promotes Syt1-PS1 interactions and dynamically modulates PS1 conformation in neurons. Therefore, we reasoned that Syt1 might be involved in regulation of the A $\beta$ production/secretion and/or PS1 conformation. To gain insight into how Syt1 may modulate $A \beta$ levels, we employed Syt1 knockdown and overexpression approaches using parental and Syt1 KD PC12 cells (Additional file 3). $\mathrm{A} \beta 40$ and $\mathrm{A} \beta 42$ levels were reduced by $37.69 \pm 2.15 \%$ and $25.63 \pm 4.31 \%(p<0.0001)$, respectively, in Syt1 KD cells (Fig. 7a). The deficits were partially rescued by transient Syt1-V5 expression in
Syt1 KD cells. Conversely, transient overexpression of Syt1-V5 in parental PC12 cells led to increased levels of both $A \beta 40$ and $A \beta 42$, by $16.30 \pm 5.46 \%$ and $22.16 \pm$ $8.66 \%(p<0.05)$, respectively. Of note, the levels of intracellular $A \beta 40$ and $A \beta 42$ were not significantly different between the parental and Syt1 KD PC12 cells (Fig. 7b), suggesting that $A \beta$ generation may be impaired.

To test whether $\mathrm{KCl} / \mathrm{Ca}^{2+}$ influx-induced changes in PS1 conformation and $A \beta$ production/secretion observed in neurons (Fig. 1b, d) are mediated by Syt1, we monitored PS1 NT-loop proximity and A $\beta 40$ and $A \beta 42$ levels in parental and Syt1 KD PC12 cells. The cells were transfected with G-PS1-R FRET reporter and treated with $\mathrm{KCl}$ in regular or $\mathrm{Ca}^{2+} / \mathrm{Mg}^{2+}$ free media. Similarly to neurons, a significant increase in the $\% \mathrm{E}_{\mathrm{FRET}}$ was observed in parental PC12 cells in the regular, $\mathrm{Ca}^{2+} / \mathrm{Mg}^{2+}$-containing (but not in the $\mathrm{Ca}^{2}$ ${ }^{+} / \mathrm{Mg}^{2+}$-free) media, indicating that $\mathrm{KCl}$-triggered pathological "closed" PS1 conformation requires the presence of $\mathrm{Ca}^{2+}$ ions (Fig. 7c). This corresponded to the $\mathrm{KCl}$-induced increase in the $\mathrm{A} \beta 40$ and $\mathrm{A} \beta 42$ levels and the $A \beta 42 / 40$ ratio in parental PC12 cells (Fig. $7 d$ ). On the contrary, no changes in PS1 conformation and

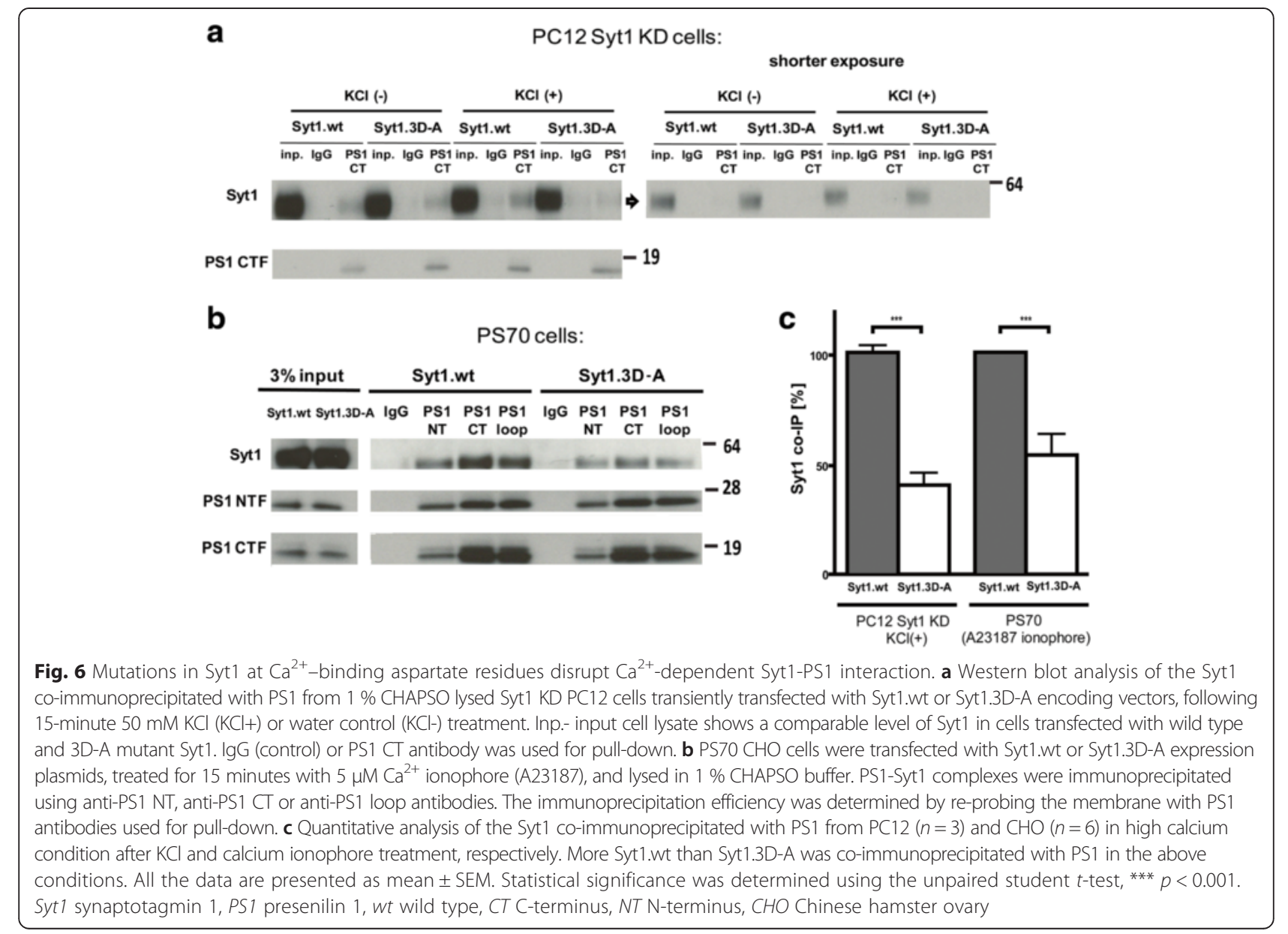




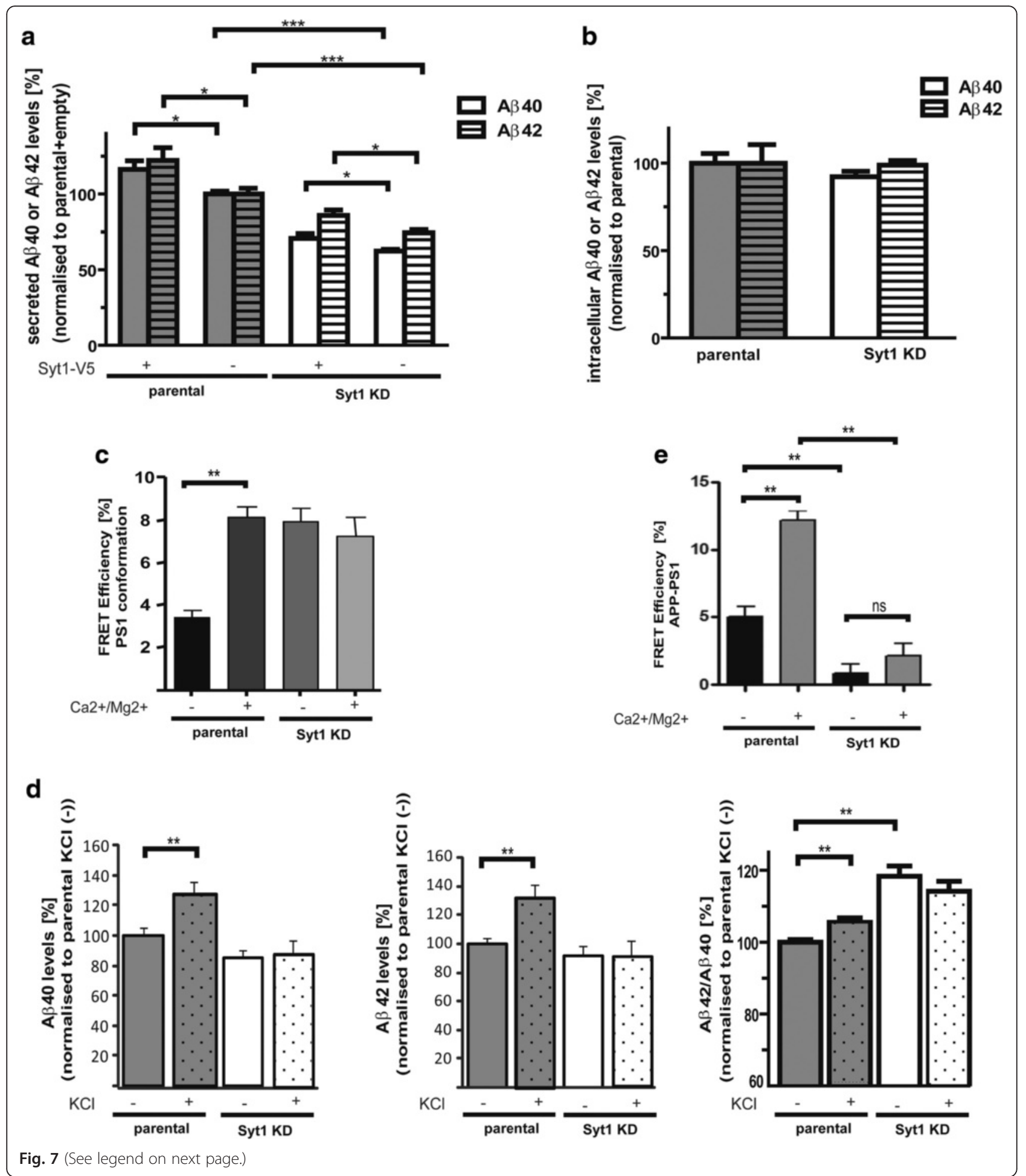




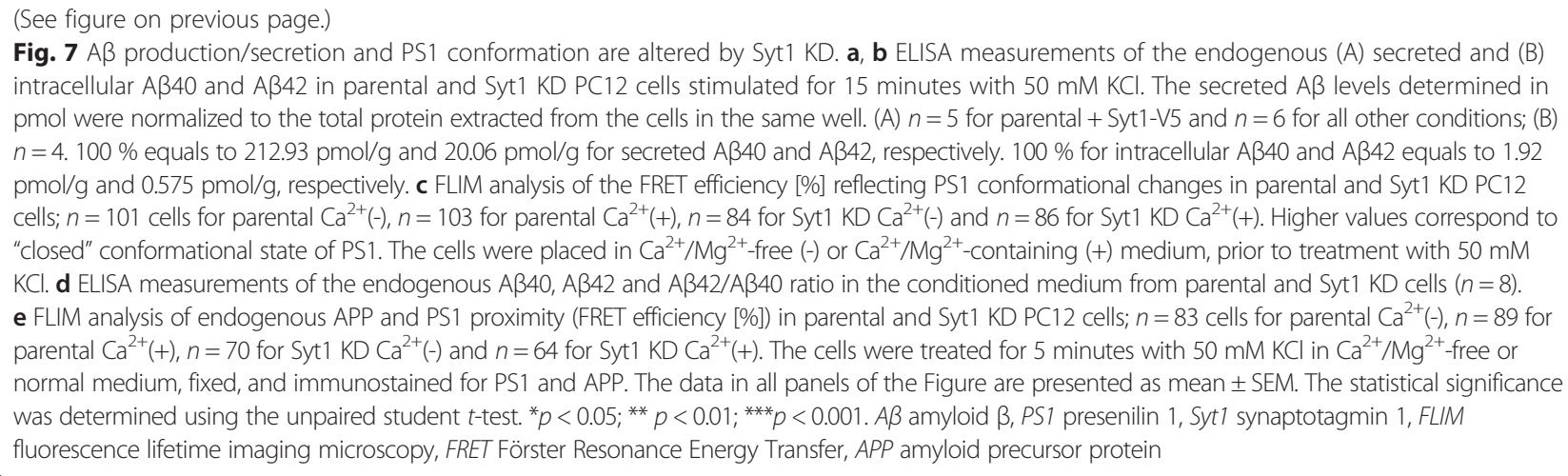

$\mathrm{A} \beta$ in response to $\mathrm{Ca}^{2+}$ influx were detected in Syt1KD cells. Interestingly, whereas $\% \mathrm{E}_{\mathrm{FRET}}$ (Fig. 7c) and the A $342 / 40$ ratio (Fig. $7 d$ ) were not affected by calcium in Syt1 KD, their baseline values were significantly higher in the absence of Syt1. These data suggest that, although the total level of $A \beta$ is reduced by Syt1 KD, the presence of Syt1 is required for the maintenance of the A $\beta 42 / 40$ ratio and PS1 in the physiological, "normal" conformation.

Since A $\beta$ levels were significantly reduced in Syt1 KD cells, we tested whether interactions between APP substrate and PS1/ $\gamma$-secretase may be affected. We detected decreased proximity between the PS1 loop domain and APP CT in Syt1 KD cells, suggesting reduced PS1-APP interaction in the absence of Syt1 (Fig. 7e). In addition, while $\mathrm{KCl}$ treatment of parental PC12 cells increased $\% \mathrm{E}_{\mathrm{FRET}}$ (PS1-APP proximity), it had no effect on the $\% \mathrm{E}_{\mathrm{FRET}}$ in Syt1 KD cells. Taken together, these data suggest that Syt1 may modulate $A \beta$ levels by influencing the assembly and/or activity of PS $1 / \gamma$-secretase and its interaction with the APP substrate.

\section{Syt 1 modulates $\boldsymbol{\gamma}$-secretase activity}

A co-IP/western-blot analysis of the PS1 CTF coimmunoprecipitation with PS1 NTF and with the other $\gamma$-secretase components in parental and Syt1 KD PC12 cells showed increased binding between PS1 CTF and NTF, as well as between PS1 and Pen-2 and Aph1a in the absence of Syt1 (Fig. 8a). This indicates that Syt1 deficiency affects $\gamma$-secretase architecture and promotes tighter association of its components. The finding is consistent with the more compact "closed" PS1 conformation in Syt 1 KD cells, as detected by the FLIM assay. At the same time, decreased levels of the PS1 N-terminal and C-terminal fragments along with the diminished Pen-2 were detected in Syt1 KD cells (Fig. 8b), suggesting reduction of the functional $\gamma$-secretase in the absence of Syt1.

To test more directly if Syt1 may affect PS1/ $\gamma$-secretase activity, we performed a cell-free in vitro $\gamma$-secretase activity assay using recombinant C100-FLAG substrate
(APP $\beta$-CTF) and membrane preparations from parental and Syt1 KD PC12 cells containing active $\gamma$-secretase. A $\sim 30 \%$ reduction of the $A \beta 40$ production was detected in Syt1 KD cells (Fig. 8c). A similar trend was recorded for $A \beta 42$ but the data did not reach statistical significance. These data confirm partial loss of $\gamma$-secretase catalytic activity in the absence of Syt1. Of note, the APP intracellular domain (AICD) level remained unaltered (Fig. 8c), supporting the hypothesis that $\gamma$-secretase cleavage of the APP $\beta$-CTF occurs in a step-wise manner [28, 29], and loss of $\gamma$-secretase activity results in "incomplete digestion" of the APP CTF substrate in Syt1 KD cells. Likewise, the $\gamma$-secretase-dependent cleavage of Notch1 at the membrane-cytoplasm interface leading to generation of the Notch1 intracellular domain (NICD) was not affected in the absence of Syt1 in PC12 Syt1 KD cells (Fig. 9).

\section{Syt1 modulates APP processing}

The role of Syt1 in APP processing was further investigated by analyzing the levels of endogenous APP Cterminal fragments and secreted APP $\beta$ ( presence and absence of Syt1 in PC12 cells. About a $22.57 \pm 5.21 \%(p<0.001)$ decrease in the total APP CTF/ FL ratio was observed in Syt1 KD cells, suggesting that $\alpha-$ and/or $\beta$-secretase cleavage of APP may be affected (Fig. 10a). Indeed, the sAPP $\beta / A P P$ FL ratio was decreased by about $32.25 \pm 9.15 \%(p<0.001)$ in the absence of Syt1 (Fig. 10a). On the other hand, in CHO cells lacking endogenous Syt1 but stably overexpressing human APP and Syt1-V5 or only APP, the APP CTF/APP FL, sAPP $\alpha /$ APP $\mathrm{FL}$, and $\mathrm{sAPP} \beta / \mathrm{APP} F \mathrm{~F}$ ratios were significantly increased in cells overexpressing Syt1 (Fig. 10b).

\section{BACE1 maturation and degradation are affected in Syt1 KD cells}

The reduced amount of SAPP $\beta$ suggests that in addition to the $\gamma$-secretase activity, BACE1 activity may also be affected in Syt1 KD cells. Indeed, the level of endogenous total BACE1 was significantly decreased, whereas the level of immature BACE1 detected by prodomain- 


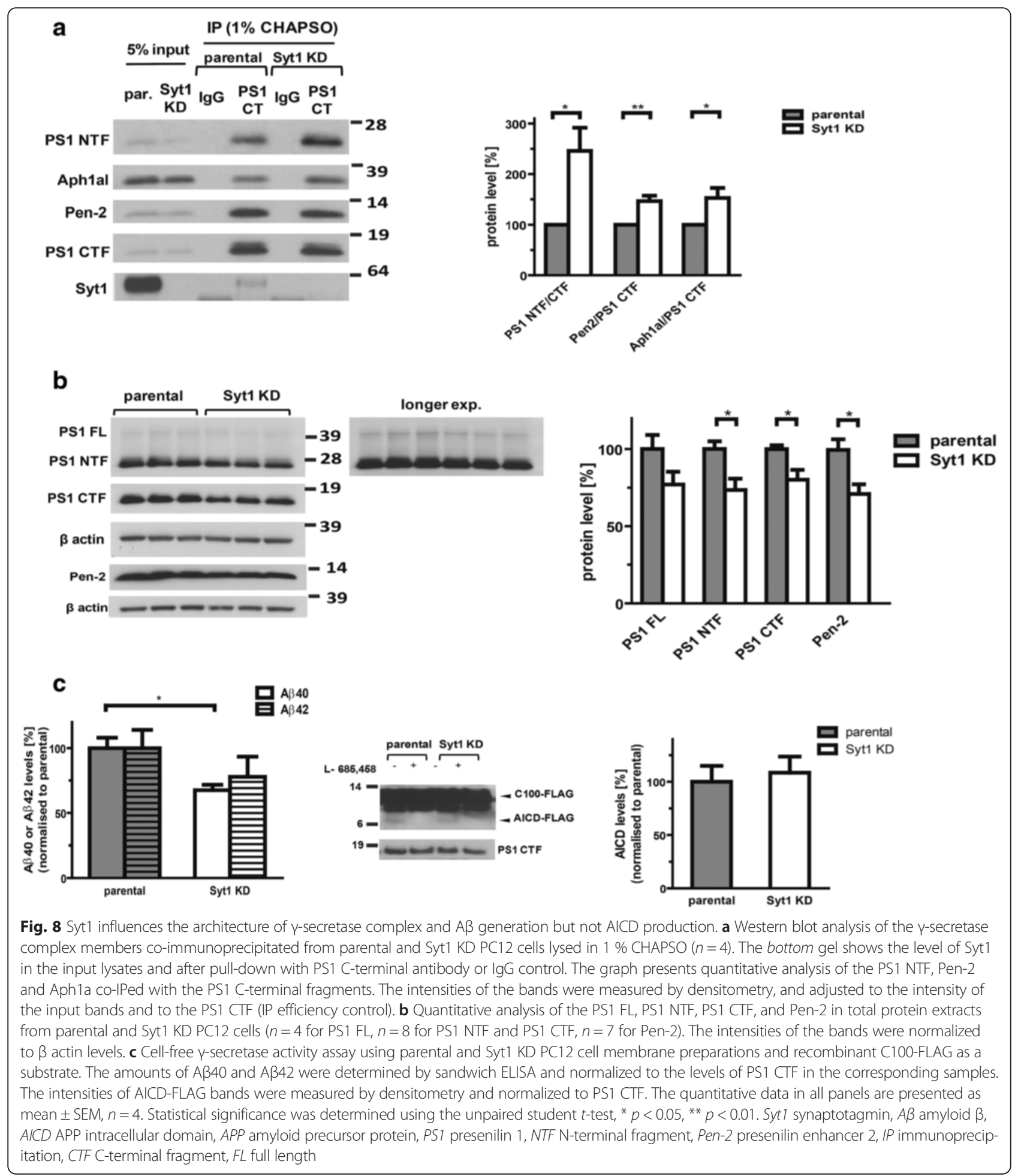

specific antibody was increased in Syt1 KD cells, relative to that in parental $\mathrm{PC} 12$ cells. Thus, the total/immature BACE1 ratio was reduced by $58.19 \pm 5.14 \%(p<0.0001)$ in the absence of Syt1 (Fig. 11a).
The low levels of mature BACE1 were at least partially due to a drastic reduction in the BACE1 protein half-life in Syt1 KD cells, as revealed by the cycloheximide pulse chase assay (Fig. 11b). Of note, no difference in the 

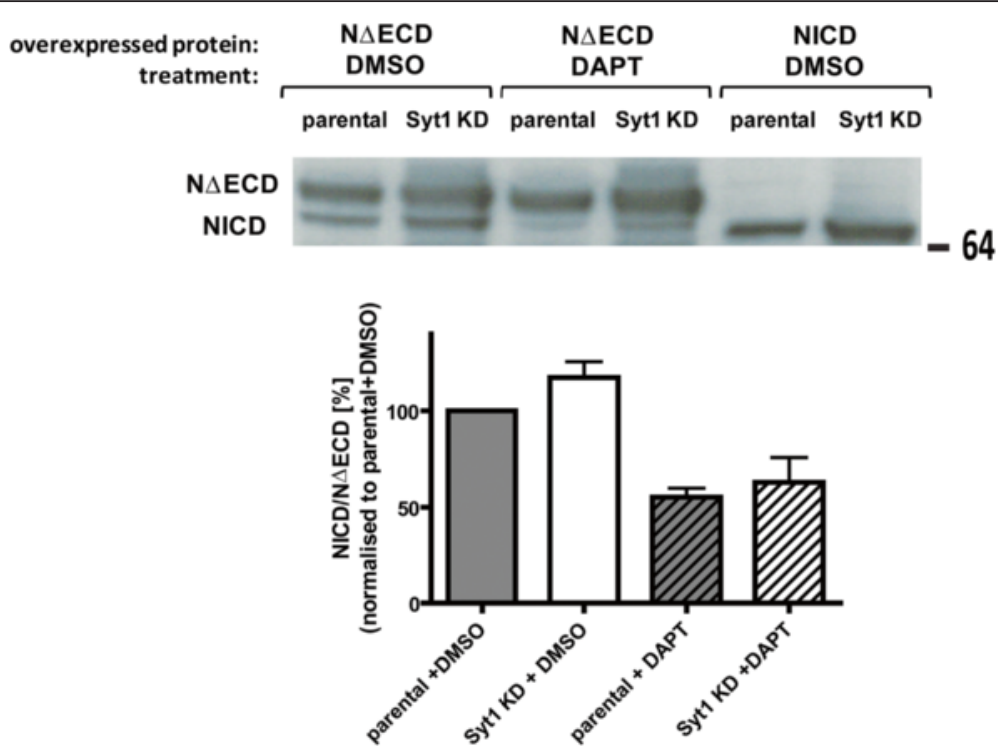

Fig. 9 Notch1 intracellular domain (NICD) generation is not affected in Syt1 KD PC12 cells. Parental and Syt1 KD PC12 cells were transfected with Myc-tagged, constitutively active Notch1 with deleted extracellular domain (NAECD), which is an immediate substrate of the $\gamma$-secretase. The cells were treated with DMSO or $\gamma$-secretase inhibitor — DAPT. Transfection with a plasmid encoding Notch1 intracellular domain (NICD) was used as a control. Western blot analysis shows no difference in the production of the Notch1 intracellular domain, as detected by anti-myc antibody, between parental and Syt1 KD PC12 cells. Data are presented as the NICD/N $\Delta E C D$ ratio; mean \pm SEM, $n=4$. Statistical significance was determined using unpaired student $t$-test. Syt1 synaptotagmin 1

stability of PS1 CTF and APP between parental and Syt1 KD cells was observed (Additional file 4).

\section{Syt1 affects localization of APP processing enzymes}

To determine whether Syt1 may modulate $A \beta$ production by influencing trafficking of BACE1, PS1 $/$-secretase, or APP, we analyzed their distribution in the parental and Syt1 KD PC12 cells using subcellular fractionation (Fig. 12a). We found that lack of Syt1 affects trafficking of PS1 CTF and BACE1 but not APP. The PS1 CTF has been retained within the earlier secretory compartments in Syt1 KD cells. On the other hand, the distribution of BACE1 has shifted towards the trans-Golgi network in the absence of Syt1.

The cell-surface biotinylation approach revealed a significantly reduced amount of BACE1 and PS1 CTF on the surface of Syt1 KD cells as compared to parental PC12 cells (Fig. 12b). However, since the levels of mature, functionally active $\gamma$-secretase (PS1 CTF/NTF) and BACE1 were considerably reduced in the absence of Syt1, we calculated the ratio of plasma membrane to total level for each of the proteins. The adjusted values were not significantly different between the cell lines, although there was a trend towards reduced PS1 CTF plasma membrane/total ratio in Syt1 KD cells, suggesting that the impaired intracellular transport of PS1 might cause this slight reduction of the PS1/ $\gamma$-secretase at the cell surface.
To determine if the observed mislocalization of PS1 and BACE1 in the absence of Syt1 was due to a broader effect of the Syt1 KD on protein trafficking, we analyzed subcellular distribution of another synaptic protein, synaptophysin (Syp), as well as other $\gamma$-secretase members/ transmembrane proteins, Nct and Pen-2, in Syt1 KD and parental PC12 cell lines (Additional file $5 \mathrm{~A}$ and B bottom panel). No major differences in the abundance of the target proteins within the respective fractions were observed between the cell lines. Furthermore, the overall transport fidelity was not noticeably altered by the lack of Syt1, as shown by comparable distribution of the compartment specific markers within the respective fractions in PC12 cells with and without Syt1 (Additional file 5B). This further reaffirms that Syt1 selectively affects PS1 and BACE1, and that their misdistribution is not due to impairments in the overall intracellular transport fidelity in the Syt1 KD cells.

\section{Syt1 is unlikely a substrate for PS $1 / \gamma$-secretase}

Since Syt1 has a relatively short $\mathrm{N}$ terminus, single-pass transmembrane domain and a larger cytoplasmic region, a structure similar to the previously known PS1 $/ \gamma$-secretase substrates, we tested if Syt1 may be a novel $\gamma$ secretase substrate. There was no difference in the levels of Syt1 and its proteolytic fragments between DMSOand $\gamma$-secretase inhibitors-treated primary neurons and mouse embryonic fibroblasts (MEF), or in MEFs lacking 


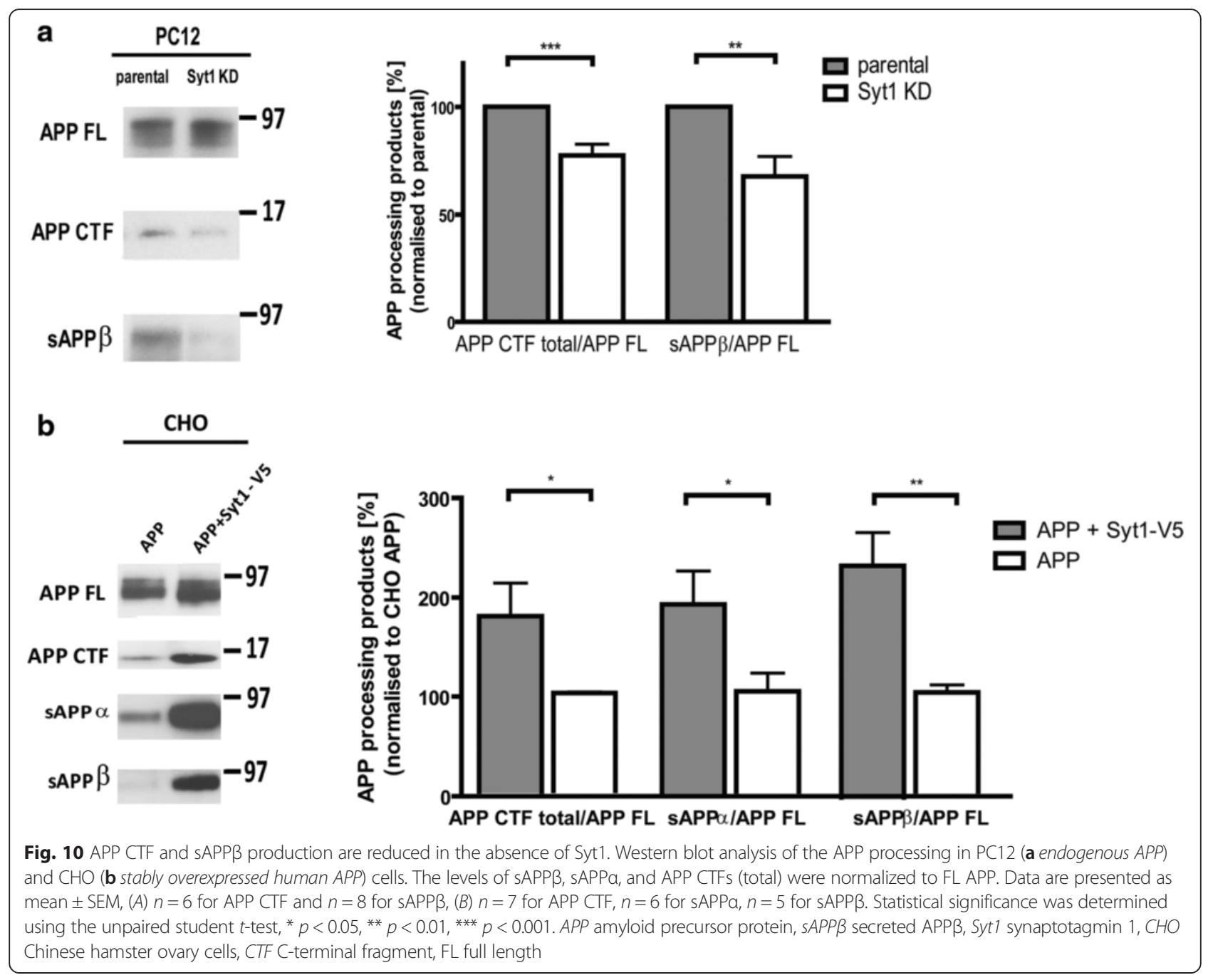

PS1/PS2 (Additional file 6). Hence, it is unlikely that Syt1 is a PS1/ $\gamma$-secretase substrate.

\section{Discussion}

Synaptotagmin 1 (Syt1), a synaptic vesicle associated protein, was identified as a novel $\mathrm{Ca}^{2+}$-dependent binding partner of presenilin 1 (PS1). Moreover, a new role of Syt1 in modulation of the PS1 conformation and A $\beta$ production via several mechanisms was revealed.

The $\mathrm{Ca}^{2+}$-dependent profile of PS1 binding to Syt1 suggests that $\mathrm{Ca}^{2+}$ may function as a switch controlling PS1 interaction with the synaptic vesicle (SV) protein intimately involved in SV exocytosis and neurotransmitter release. An involvement of presenilins in the activity-dependent regulation of neurotransmission was shown by Zhang et al. [30], reporting $\mathrm{Ca}^{2+}$-linked impairment of synaptic facilitation and neurotransmitter release as a result of selective prebut not post-synaptic inactivation of PS1/2. Together, these findings suggest that PS1 may be involved in regulation of the neurotransmitter release via $\mathrm{Ca}^{2+}$-triggered interaction with Syt1. In addition, our study shows that since presynaptic terminals are the major sites of the $\mathrm{Ca}^{2+}$-induced interaction in neurons, as determined by FLIM (Fig. 5b), Syt1 might play a role in modulation of the $\mathrm{A} \beta$ production/secretion locally at the synaptic terminals. This does not, however, exclude the role of Syt1 in A $\beta$ production away from the synapse and/or in a PS1-independent manner.

Synaptic activity and $\mathrm{Ca}^{2+}$ flux are tightly linked to $\mathrm{A} \beta$ production $[11-13,31]$ but the molecular mechanisms underlying modulation of the $\mathrm{A} \beta$ production at the synapse remain elusive. A sustained release of the neurotoxic A 342 species in response to stimulation of isolated nerve terminals [21], and deposition of oligomeric $A \beta$ at the excitatory synapses in the brain were reported [32, 33]. The formation of $A \beta$ oligomers and their neurotoxicity depends not only on the increased amount of $A \beta$ but more importantly on the A $\beta 42 / 40$ ratio [34]. Familiar AD causing mutations in PS1, PS2, or APP consistently increase the relative ratio between the $A \beta 42$ and $A \beta 40$ peptides, irrespective of the individual levels of $A \beta 42$ and 


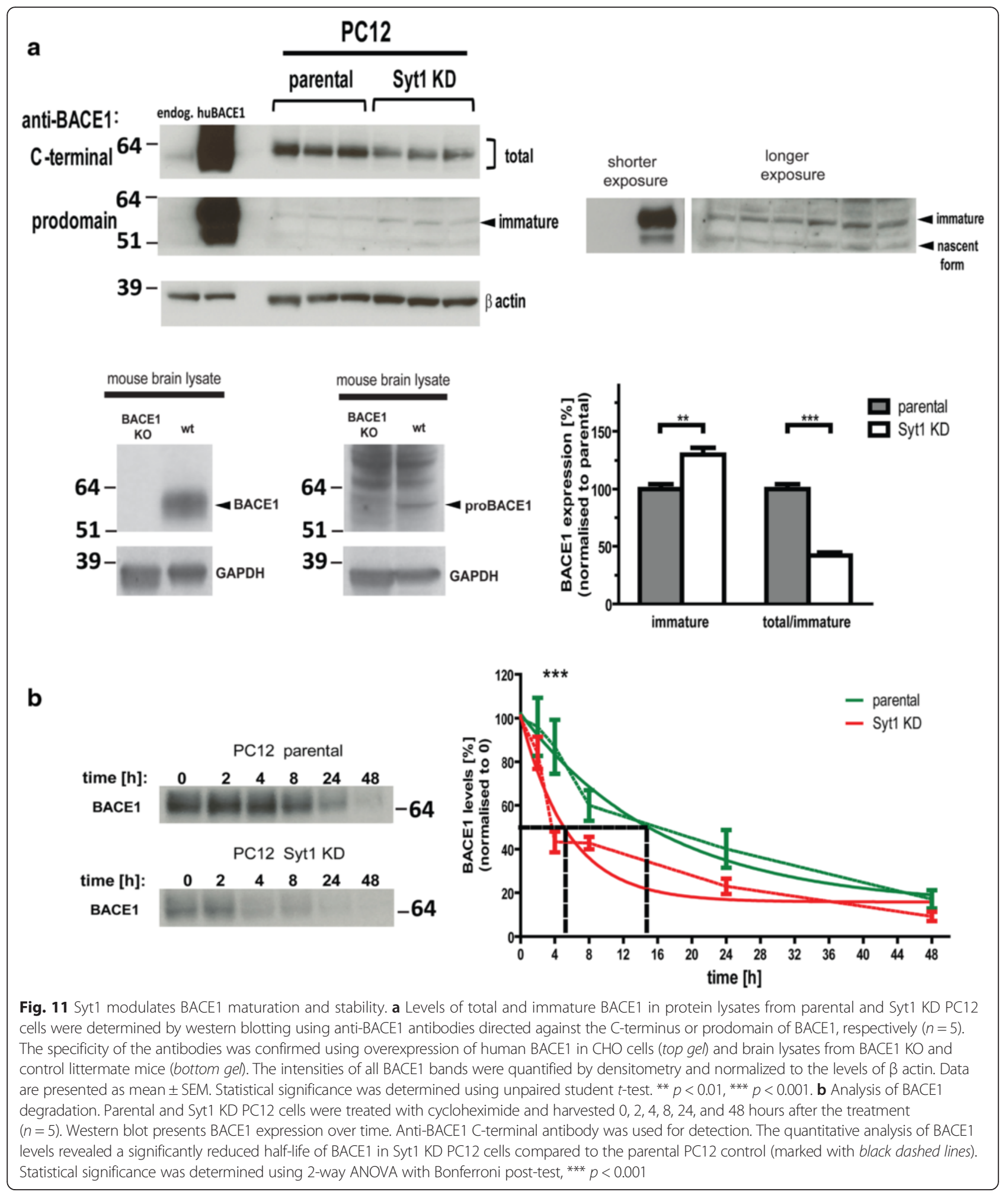

A $\beta 40$ [35-37]. We have previously reported that increased A $\beta 42 / 40$ ratio is tightly linked to pathogenic "closed" conformation of PS1 [22, 23, 25, 38]. Concomitant with these findings, our current study demonstrates that continuous neuronal activation and elevated intracellular calcium induce pathogenic "closed" conformation of PS1, and provide a mechanistic explanation of the observed targeted accumulation of $A \beta$ oligomers at the synapse.

Structural changes in PS1 are observed during normal aging, they precede $\mathrm{A} \beta$ plaque deposition, and are 


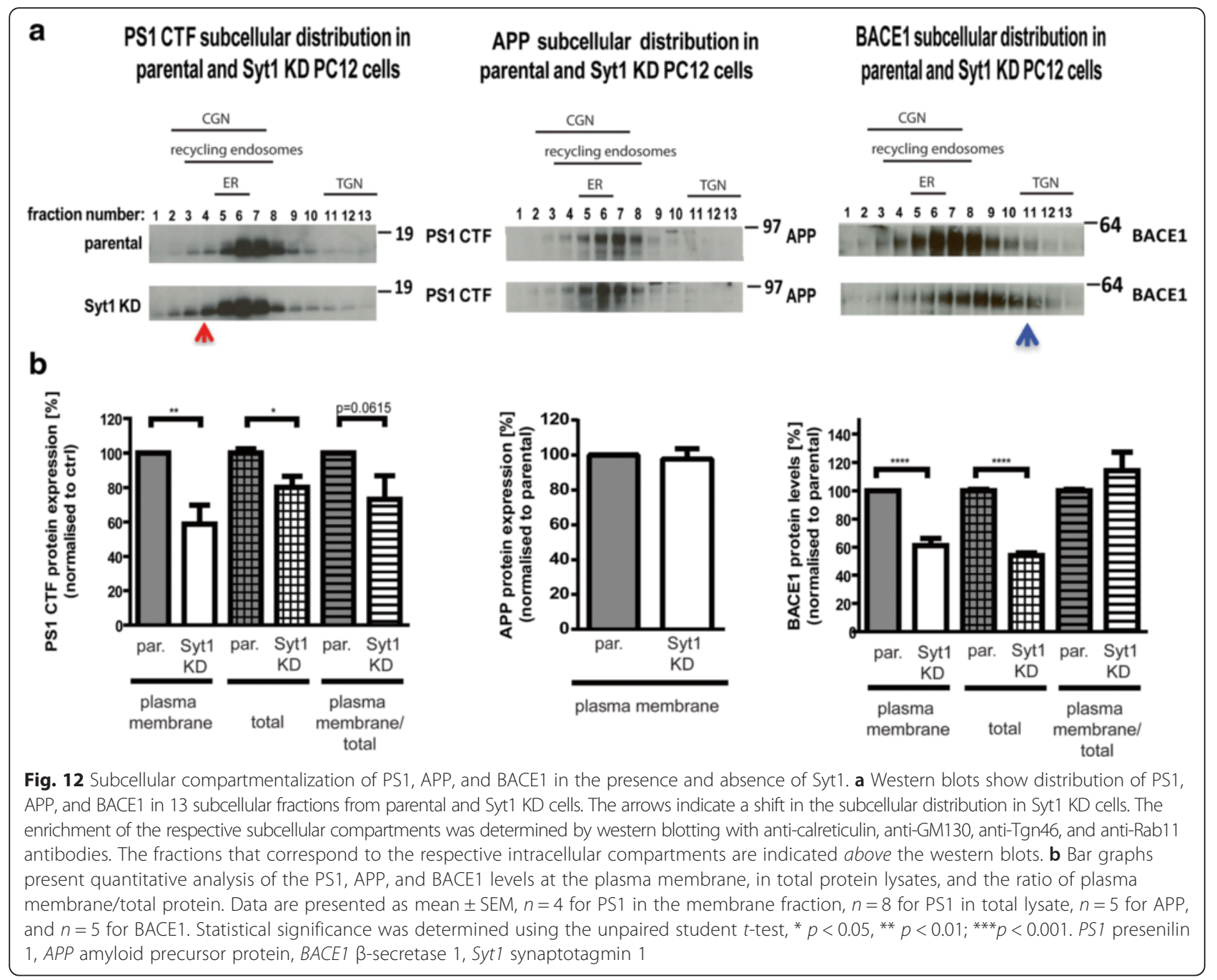

exacerbated in sporadic AD brains [39]. We propose that $\mathrm{PS} 1 / \gamma$-secretase exists in a dynamic equilibrium of different conformational states, which we call "closed" and "open" based on the FRET measurements, that may modulate PS1 function $[23,25]$. Although it is possible that familial $A D$ (fAD) mutations in PS1 [23] or recruitment of Aph1B isoform [38] produce more stable $\gamma$-secretase complexes with PS1 in pathogenic "closed" conformation, our current study shows that allosteric changes in the pre-existing $\gamma$ secretase complexes can occur in response to $\mathrm{Ca}^{2+}$. Importantly, these changes are reversible, as shown after a brief puff of glutamate, and closely correlate with the cytosolic $\mathrm{Ca}^{2+}$ level. We demonstrate that in addition to promoting "closed" PS1 conformation, prolonged depolarization of neurons and continuing high intracellular $\mathrm{Ca}^{2+}$ also increased the level of both $A \beta 40$ and $A \beta 42$ and, importantly, led to an increased $A \beta 42 / 40$ ratio. These data are consistent with Kim et al. [21] reporting a similar increase in $A \beta 42$ levels after $\mathrm{KCl}$-induced depolarization of isolated nerve terminals, synaptoneurosomes, and are in line with the early detection of $A \beta$ deposits in the default mode network of asymptomatic older adults [10]. Interestingly, a spikeburst stimulation of hippocampal neurons increased release of only $A \beta 40$ but not $A \beta 42$, accompanied by PS1 conformational changes consistent with reduced FRET efficiency [40]. These data suggest that diverse stimuli and/or their duration may have different outcomes, with continued activation and/or persistent high calcium inducing pathogenic change in $\mathrm{PS} 1 / \gamma$-secretase and elevated $A \beta 42 / 40$ ratio that would ultimately lead to $A \beta$ deposition in the brain.

Our current study reveals that Syt1 may be required for the maintenance of the physiological "open" PS1 conformation, as pathogenic conformational change of PS1 was detected in the absence of Syt1. Consistent with the PS1 conformational change, the ratio of $A \beta 42$ to A $\beta 40$ was elevated in Syt1 KD cells, although the level of both $A \beta 40$ and $A \beta 42$ was significantly reduced in the absence of endogenous Syt1 and increased by transient Syt1-V5 overexpression. This is consistent with our findings in stably Syt1 transfected PC12 and CHO cells [41]. 
Interestingly, whereas $\mathrm{KCl}$ treatment induced PS1 conformational change and triggered $\mathrm{A} \beta$ production in neurons and parental PC12 cells, it had no effect on either in Syt1 KD cells. Thus, it is highly likely that in addition to its role in exocytosis, Syt1, presenting a strong and specific synaptic expression pattern in neurons, may also modulate $A \beta$ production/secretion locally at the synaptic terminals.

We identified several molecular mechanisms that underlie Syt1-mediated regulation of A $\beta$, both PS1 interactiondependent and independent. Syt1 and its interaction with PS1 may be needed for maintaining PS1 in the "open" conformation, and modulation of specific $A \beta$ species produced. We observed tighter association of the $\gamma$-secretase components (consistent with the "closed" PS1 conformation), diminished amount of PS1 NTF/CTF, and reduced $\gamma$-secretase activity in Syt1 KD compared to parental cells, indicating that architecture and activity of the $\gamma$-secretase complex are impaired in the absence of Syt1. Importantly, whereas A $\beta$ production was reduced by Syt 1 KD, the PS1/ $\gamma$-secretase dependent epsilon and S3 cleavages, responsible for AICD and NICD generation, respectively, were not affected. This finding is consistent with the step-wise $\gamma$-secretase cleavage model that proposes a three amino acid spaced cleavage mechanism for $\gamma$-secretase mediated intramembrane proteolysis $[28,29,42]$. The effect of Syt1 $\mathrm{KD}$ is also in agreement with the proposed $\gamma$-secretase loss-of-function due to familial AD mutations in PS1, which also display "closed" conformation and biochemically result in a partial loss of the $\gamma$-secretase activity due to inability of 'complete digestion' of the APP substrate, generating fewer but longer $A \beta s$ (for review see [37]).

Calcium binding to Syt1 activates SV release machinery [18] and, hence, may promote exocytosis of $A \beta$ at the synapse. Indeed, active PS1 $\gamma$-secretase complex, APP and BACE1 were found in SVs enabling A $\beta$ production within the vesicles ([43-47] and this study).

Moreover, we found that Syt1 knockdown selectively impairs intracellular trafficking of PS1 and BACE1 and, thus, may affect $A \beta$ via trafficking abnormalities and away from the synapse. Syt1 is also a direct binding partner of APP [41, 48] and, therefore, may regulate APP processing by acting as a chaperon for APP and/or PS1, influencing their subcellular localization, alignment and interaction. Indeed, our FLIM assay revealed diminished APP-PS1 proximity in the absence of Syt1, which could be due to observed mislocalization of PS1 in the Syt1 KD cells. Finally, we demonstrate that Syt1 expression is crucial for localization, maturation, and stability of BACE1; thus, it may also modulate earlier steps of the APP processing. We found that the subcellular localization of BACE1 but not APP is altered in the absence of Syt1. This is consistent with other studies showing that trafficking of APP and BACE1, namely surface-to-endosome transport and sorting, could be distinctly regulated within the cell [49-51]. It should also be mentioned that since PS1 is involved in BACE1 maturation [52], there is a possibility that affected PS1 function in Syt1 KD has a downstream effect on BACE1.

Taken together these findings provide compelling evidence supporting a role of Syt1 in $A \beta$ production. Namely, in addition to facilitation of the $A \beta$ secretion via exocytosis, Syt1 plays a direct role in the activitymediated regulation of APP processing by: (1) modulating PS1 $\gamma$-secretase conformation, catalytic activity, and interactions with APP; (2) affecting BACE1 maturation and stability; and (3) mediating BACE1 and PS1 subcellular compartmentalization.

The discovery of the novel $\mathrm{Ca}^{2+}$-dependent interactions between PS1 and Syt1 links several well-established players implicated in AD pathogenesis, such as elevated $\mathrm{Ca}^{2+}$, structural changes in $\mathrm{PS} 1 / \gamma$-secretase, and toxic A 342 specie generation with synaptic proteins critical for $\mathrm{SV} /$ neurotransmitter release. It also provides strong evidence for Syt1 being a $\mathrm{Ca}^{2+}$-sensitive modulator of the PS1 $\gamma$-secretase, APP processing, and consequent A $\beta$ production and deposition at the pre-synapse, suggesting a new role for Syt1 in neurodegeneration. Lack of the Syt1 effect on Notch1 ICD generation may encourage novel synapse-specific therapeutic strategies targeting Syt1-PS1 interaction.

\section{Conclusions}

Synaptic loss caused by local accumulation of the oligomeric amyloid $\beta(A \beta)$ is the strongest and the earliest correlate of Alzheimer's disease dementia. However, events and proteins that influence synaptic $A \beta$ accumulation are poorly understood. In a search for early modifiers of the synaptic $A \beta$ we identified synaptic protein, synaptotagmin 1 (Syt1), as a novel calcium-regulated interactor of the $\mathrm{A} \beta$ cleaving enzyme, presenilin 1 (PS1)/ $\gamma$-secretase. We found that Syt1 may function as activity-dependent regulator of the synaptic $A \beta$ by modulating PS1 catalytic activity and conformational state, BACE1 maturation and stability. These novel discoveries provide a mechanistic link between major players implicated in $\mathrm{AD}$ pathogenesis: high calcium, toxic $\mathrm{A} \beta 42$ specie, $\mathrm{PS} 1 / \gamma$-secretase conformational changes, and synapse. Furthermore, these findings may open avenues for new, synapse-targeting therapeutic strategies to halt the Alzheimer's disease progression.

\section{Methods}

\section{Expression plasmids}

The GFP-PS1-RFP (G-PS1-R) construct encoding wild type (wt) human presenilin 1 (PS1) with enhanced green fluorescent protein (EGFP) fused to the $\mathrm{N}$-terminus and red fluorescent protein (RFP) inserted into the loop 
domain of PS1 was used for the fluorescence life time imaging (FLIM) assay of PS1 conformational changes [25]. The constructs with EGFP fused to the N-terminus of PS1 (G-PS1), RFP inserted into the loop domain of PS1 (PS1-R), and RFP-GFP fusion (R-G fusion) plasmid, in which RFP is fused to the N-terminus of EGFP with a short linker, were used as controls.

Human wt synaptotagmin 1 (Syt1) was cloned into $\mathrm{pcDNA}^{\mathrm{m}} 6$ V5 Myc expression vector (Life Technologies, Grand Island, NY). Mutations that affect calcium binding to Syt1 (D230A, D309A, and D365A) were introduced using a QuickChange site-directed mutagenesis kit (Stratagene, La Jolla, CA) to generate Syt1 3D-A plasmid. The empty pcDNA ${ }^{\mathrm{m}} 6$ V5 Myc vector was used as a control.

pCS2 Notch1 $\triangle$ EC-6MT vector encoding C-terminally Myc-tagged and N-terminally truncated Notch 1 receptor construct $(\mathrm{N} \triangle \mathrm{ECD})$, which does not require ligand binding for its activation and represents an immediate substrate of $\gamma$-secretase, and pCS2 Notch1 ICD-6MT plasmid encoding the intracellular domain of murine Notch1 (NICD) were gifts from Dr. R. Kopan (Washington University, St. Louis).

\section{GST protein cloning, purification, and LC-MS/MS analysis}

The protocol used for GST protein cloning and purification was adapted from [53]. Briefly, DNA fragments encoding human presenilin $1 \mathrm{~N}$-terminus (PS1 NT) (amino acids 1-80), PS1 loop 1-2 (amino acids 98-134), and PS1 loop 6-7 (amino acids 263-376) were subcloned into the glutathione S-transferase (GST) expression vector pGEX-6P-2 (GE Healthcare Life Sciences, Pittsburgh, PA) to create corresponding PS1 fragmentGST fusion peptides. For GST protein purification, Escherichia coli BL21 (fhuA2 [lon] ompT gal [dcm] $\Delta h s d S$ ) cells were transformed with the plasmids and the protein expression was induced by the addition of $1 \mathrm{mM}$ isopropyl-D-thiogalactoside (IPTG). The bacterial cultures were centrifuged at $3500 \mathrm{xg}$ for 20 minutes at $4{ }^{\circ} \mathrm{C}$, the pellet was resuspended in TBST and the bacterial suspensions were sonicated. The lysates were clarified by centrifugation at $14,000 \mathrm{xg}$ for 15 minutes at $4{ }^{\circ} \mathrm{C}$, and then incubated with washed glutathione-Sepharose $4 \mathrm{~B}$ beads.

Mouse brain lysates prepared in $1 \%$ Triton X-100 icecold lysis buffer (see below) were used for MS analysis. The soluble supernatant fraction was divided into equal aliquots that were incubated with GST-PS1 peptides, immobilized on a column in $\mathrm{Ca}^{2+}$-free or $2 \mathrm{mM} \mathrm{CaCl}$ conditions. The recombinant GST peptide was used as a control. The bound proteins were eluted with 2xSDS NuPage sample buffer (Life Technologies, Grand Island, $\mathrm{NY}$ ) and separated by electrophoresis using 4-12 \% $1.5 \mathrm{~mm}$ Bis-Tris NuPage gels (Life Technologies, Grand
Island, NY). The gels were stained with coomassie blue stain (Life Technologies, Grand Island, NY), and several bands that displayed differential protein profile between GST-control and GST-PS1 pull-down, between GST-PS1 pull-down from brain lysates vs. lysis buffer, and between the $\mathrm{Ca}^{2+}(+)$ and $\mathrm{Ca}^{2+}(-)$ conditions were excised, and sent to Harvard University's Taplin Biological Mass Spectrometry Facility (https://taplin.med.harvard.edu/) for analysis.

\section{Mouse brain lysates}

Brain cortices were dissected from 2- to 3-month-old wild type (wt) CD1 mice (Charles River Laboratories, Wilmington, MA) and homogenized in a buffer containing $50 \mathrm{mM}$ HEPES, $125 \mathrm{mM} \mathrm{NaCl}, 0.1 \mathrm{mM}$ EDTA, $100 \mathrm{mM}$ sucrose, protease inhibitors (Roche, Indianapolis, Indiana) and $1 \%$ Triton X-100 (Tx-100) or $1 \%$ 3-[(3-cholamidopropyl) dimethylammonio]-2-hydroxy1-propanesulfonate (CHAPSO)). Brain lysates were incubated for 1 hour at $4{ }^{\circ} \mathrm{C}$ and centrifuged at $14,000 \mathrm{xg}$ to collect the soluble fractions, which were subjected to mass spectrometry (MS), immunoprecipitation (IP) and western blot analyses. All experiments that involve use of the mouse brain tissue were approved by the Subcommittee for Research Animal Care at the Massachusetts General Hospital.

\section{Synaptoneurosome (SNS) extraction}

SNSs were isolated as described previously [54] with minor modifications. In brief, cortices from 3-month-old CD1 male mice were mechanically homogenized in $1.5 \mathrm{ml}$ ice cold buffer A ( $25 \mathrm{mM}$ HEPES, $120 \mathrm{mM} \mathrm{NaCl}, 5 \mathrm{mM} \mathrm{KCl}$, $1 \mathrm{mM} \mathrm{MgCl}_{2}$ ) supplemented with $2 \mathrm{mM}$ dithiothreitol (DTT), protease inhibitor (Roche, Indianapolis, Indiana), and phosphatase inhibitor cocktails 2 and 3 (SigmaAldrich, St. Louis, MO). Samples were filtered through two layers of $80 \mu \mathrm{m}$ nylon filters (Millipore, Temecula, CA) to remove cellular debris. A total of $200 \mu \mathrm{l}$ from each sample was saved, mixed with $200 \mu \mathrm{l}$ water and $70 \mu \mathrm{l} 10 \%$ SDS, passed through a 27 -gauge needle, and boiled for 5 minutes to be used as a total extract. The remaining homogenates were filtered through a $5 \mu \mathrm{m}$ Supor membrane filter (Pall Corp., Port Washington, NY) to remove large organelles and nuclei, and the filtrates were centrifuged at $1000 \mathrm{xg}$ for 10 minutes to pellet SNSs. The pellets were resuspended in buffer $\mathrm{A}$ and used for immunostaining or were lysed in buffer B $(50 \mathrm{mM}$ Tris, $1.5 \%$ SDS, and 2 mM DTT) and used for immunoprecipitation and western blotting.

\section{Antibodies}

The following primary antibodies were used: anti-PS1 NT raised against the N-terminus of human PS1 (H-70, sc7104, Santa Cruz Biotechnology, Santa Cruz, CA, and 
MAB1563, Millipore, Temecula, CA); anti-PS1 CT raised against the C-terminus of human PS1 (D3901, Cell Signaling Technology, Danvers, MA); anti-PS1 loop raised against the loop domain between transmembrane domains 6 and 7 of human PS1 (2094-1, Epitomics, Burlingame, CA, and MAB5232, Millipore, Temecula, CA); ASV30 anti-synaptotagmin 1 (Syt1) raised against rat brain synaptic junctional complexes (MA125568, Pierce, Rockford, IL); anti-Syt1 raised against the C-terminus of rat Syt1 (MAB5200, Millipore, Temecula, CA); anti-V5 (R960-25, Life Technologies, Grand Island, NY); anti-FLAG (F1804, Sigma-Aldrich, St. Louis, MO), anti-synapsin 1 (Syn1) (D12G5, Cell Signaling Technology, Danvers, MA); antinicastrin (PRS3985, Sigma-Aldrich, St. Louis, MO); antiPen-2 (P5622, Sigma-Aldrich, St. Louis, MO); anti-Aph1aL (PRB-550P, Covance, Dedham, MA); anti-amyloid precursor protein (APP) CT (A8717, Sigma-Aldrich, St. Louis, MO); anti-APP NT (MAB348, Millipore); anti-sAPP $\beta$ (18957, IBL America, Minneapolis, MN); anti-APP (597) (28055, IBL America, Minneapolis, MN); APP C66 (custom); anti-BACE1 (D10E5, Cell Signaling Technology, Danvers, MA); anti-BACE1 raised against the prodomain (LS-C51629, LifeSpan Biosciences, Seattle, WA); anti-actin (4968, Cell Signaling Technology, Danvers, MA), anti-Na ${ }^{+} / \mathrm{K}^{+}$ATPase (AB7671, Abcam, Cambridge, MA); antiRab11 (610656, BD Biosciences); anti-Tgn46 (AB16059, Abcam, Cambridge, MA); anti-GM130 (610822, BD Biosciences, San Jose, CA); anti-calreticulin (612136, BD Biosciences, San Jose, CA), anti-GFP (632380, Clontech, Madison, WI), and anti-Myc (MA1-980, Pierce, Rockford, IL). Alexa Fluor 488 and Cy3-labeled corresponding secondary antibodies (Life Technologies, Grand Island, NY) were used for confocal microscopy imaging, and horseradish peroxidase (HRP)-conjugated ones (Pierce, Rockford, IL) for western blotting.

\section{Immunoprecipitation and western blotting}

Hippocampal brain tissue from wt 3-month-old male CD1 mice was homogenized in 9 volumes of $1 \%$ CHAPSO buffer (50 mM HEPES, $100 \mathrm{mM} \mathrm{NaCl}$, pH 7.1 and $1 \%$ CHAPSO) using plastic pestle homogenizers. Pelleted SNS fractions from wt mice brain cortex and cultured cells were homogenized by pipetting in $1 \%$ CHAPSO or $1 \%$ Tx-100 buffer (50 mM HEPES, $100 \mathrm{mM} \mathrm{NaCl}, \mathrm{pH} 7.4$, and $1 \% \mathrm{Tx}-100)$ and then passing through a 27 -gauge needle. All lysis buffers were supplemented with HALT protease and phosphatase inhibitor cocktails (Fisher, Pittsburg, PA). The homogenates were rotated at $4{ }^{\circ} \mathrm{C}$ for 1 hour, centrifuged at 20,000xg for 20 minutes and the supernatants were collected as samples for IP. Total protein concentrations were determined by Thermo Scientific ${ }^{\mathrm{Tx}}$ Pierce $^{\mathrm{Tm}} \mathrm{BCA}^{\mathrm{mm}}$ Protein Assay (Pierce, Rockford, IL).
Aliquots of the supernatant containing equal amounts of total protein were incubated with anti-PS1 NT, antiPS1 CT, anti-PS1 loop, or anti-Syt1 antibodies overnight at $4{ }^{\circ} \mathrm{C}$ with end-over-end rotation. Normal rabbit IgG or mouse anti-FLAG antibodies were used as negative controls. After the overnight incubation, 20-30 $\mu \mathrm{l}$ of Protein G Dynabeads (Life Technologies, Grand Island, NY) were added to each sample and incubated for 10 minutes at room temperature. The Dynabeads were collected and washed twice with $1 \%$ CHAPSO buffer and once with wash buffer (50 mM HEPES, $100 \mathrm{mM} \mathrm{NaCl}, \mathrm{pH}$ 7.4) or three times with $1 \% \mathrm{Tx}-100$ buffer. Bound proteins were eluted by boiling at $95{ }^{\circ} \mathrm{C}$ for 5 minutes with 2xLDS sample buffer (Life Technologies, Grand Island, NY) containing $4 \%$-mercaptoethanol.

Immunoprecipitated or total protein was separated by SDS-PAGE on $4-12 \%$ or $10 \%$ Bis-Tris NuPage polyacrylamide gels (Life Technologies, Grand Island, NY). After the electrophoresis, protein was transferred to nitrocellulose membranes (GE Healthcare Lifesciences, Pittsburgh, PA) and probed with respective primary and corresponding HRP-conjugated secondary antibodies. The blots were developed using ECL Western Blotting Substrate (Pierce, Rockford, IL) and exposed on X-ray films (Amersham Hyperfilm ECL). The intensity of respective protein bands was quantified using ImageJ 1.46c software. When necessary, antibodies were stripped using One Minute WB Advance Stripping Buffer (GM Biosciences, Rockville, MD).

\section{Cell cultures and transfection}

Primary neuronal cultures were obtained from 16- to 18-day-old embryos of CD1 wild-type mice. Cortical and hippocampal neurons were extracted using a Papain Dissociation Kit (Worthington Biochemical Corporation, Lakewood, NJ) and plated onto tissue culture grade dishes and slides coated with poly-D-lysine. Cells were cultured for 12-28 days in vitro (DIV) in Neurobasal Media supplemented with $2 \%$ B27 supplement, $1 \%$ penicillin/streptomycin, $1 \%$ Glutamax (Life Technologies, Grand Island, $\mathrm{NY}$ ) in $37^{\circ} \mathrm{C}, 5 \% \mathrm{CO}_{2}$ incubator.

Rat pheochromocytoma cell line (PC12) stably expressing short hairpin RNA (shRNA) specifically silencing the expression of Syt1, referred to as Syt1 KD $\mathrm{PC} 12$, and the parental PC12 cell line were kindly provided by Dr. Amy B. Harkins (St. Louis University School of Medicine) [55]. The cells were grown in RPMI Medium 1640 supplemented with $10 \%$ heat-inactivated horse serum, $5 \%$ fetal bovine serum (FBS), and $1 \%$ penicillin/streptomycin (Pen/Strep) (Life Technologies, Grand Island, NY) in a $37{ }^{\circ} \mathrm{C}, 5 \% \mathrm{CO}_{2}$ incubator. For biochemical or microscopy (optical imaging) analyses, they were plated into $10 \mathrm{~cm}$ Petri dishes (Becton Dickinson 
Labware, Franklin Lakes, NJ) or $35 \mathrm{~mm}$ glass-bottom culture dishes (MatTek Corp, Ashland, MA), respectively. When needed, cells were transfected with selected expression plasmids using Lipofectamine LTX and Plus reagents (Life Technologies, Grand Island, NY).

PS double-knockout (PS-/-) mouse embryonic fibroblasts (MEF) and PS-/- stably transfected with wt hu PS1 were provided by Dr. B. De Strooper (Belgium). Chinese hamster ovary $(\mathrm{CHO})$ cell lines expressing human wt APP and PS1 (PS70) were gifts from Dr. Selkoe (Boston, MA). CHO cells stably expressing human wt APP and Syt1-V5 were generated in Dr. Kovacs lab (Boston, MA). All the cell lines were cultured in OptiMEM $^{\circ}$ I Reduced Serum medium supplemented with $5 \%$ FBS (Life Technologies, Grand Island, NY), and respective selection antibiotics in a $37{ }^{\circ} \mathrm{C}, 5 \% \mathrm{CO}_{2}$ incubator. When necessary, the cells were transfected with other expression plasmids using Lipofectamine LTX (Life Technologies, Grand Island, NY).

\section{Spectral Förster resonance energy transfer (FRET)}

Primary neurons (12-14 days in vitro [DIV 12-14]) were cultured in phenol red-free culture medium and transfected with G-PS1-R expression plasmid as a reporter of PS1 conformational changes, or G-PS1, R-PS1, and G-R fusion constructs as controls for determining spectral FRET settings using Metadetector on a Zeiss LCM510 microscope as described [25]. For the time-lapse recording, neurons were imaged twenty-four hours after the transfection with G-PS1-R. An argon laser at $488 \mathrm{~nm}$ was used to excite GFP, and emitted fluorescence was detected within $513 \pm 10.57 \mathrm{~nm}$ (GFP) and $598 \pm 10.57 \mathrm{~nm}$ (RFP) spectral bandwidth of the Metadetector [25]. The fluorescence signal was recorded every $\sim 30$ seconds using a Zeiss LCM510 microscope equipped with $37{ }^{\circ} \mathrm{C}, 5 \%$ $\mathrm{CO}_{2}$ incubation chamber.

The G-PS1-R transfected neurons were imaged for $5 \mathrm{mi}$ nutes to set up the baseline RFP/GFP ratio. Then, $100 \mu \mathrm{l}$ of $50 \mathrm{mM} \mathrm{KCl}$ or $\mathrm{H}_{2} \mathrm{O}$ were added directly into the dish or $10 \mu \mathrm{l}$ of $1 \mathrm{M}$ L-glutamate (Glu) (Sigma-Aldrich, St. Louis, MO) were squirted directly onto imaged neuron, and changes in the fluorescence intensity were recorded for up to $60(\mathrm{KCl})$ or $15(\mathrm{Glu})$ minutes post-treatment. In the control experiment, to prevent $\mathrm{Ca}^{2+}$ influx into the Glu-treated neurons, culture medium was replaced with Hanks Balanced Salt Solution without $\mathrm{Ca}^{2+}$ and $\mathrm{Mg}^{2+}$ (Life Technologies, Grand Island, NY).

The acquired images were analyzed using LSM Image Browser. A ratio of $598 \mathrm{~nm}$ (RFP) to $513 \mathrm{~nm}$ (GFP) was used as readout of the FRET efficiency $\left(\% \mathrm{E}_{\mathrm{FRET}}\right)$ ( $\mathrm{R} / \mathrm{G}$ ratio), which reflects relative proximity between the RFP and the GFP fluorophores. A ratiometric pseudo-color image was produced using Image $1.46 \mathrm{c}$ software, by dividing the average pixel fluorescence intensity of an image in the $598 \mathrm{~nm}$ spectral window by that in the $513 \mathrm{~nm}$ window, after subtracting the background fluorescence. The Look-Up Table (LUT) was applied by mapping image values to color-scale (16 colors) resulting in the pseudo-color image.

\section{Calcium imaging}

To measure changes in intracellular $\mathrm{Ca}^{2+}$ levels, primary neurons were pre-loaded with $5 \mu \mathrm{M}$ Oregon Green 488 BAPTA-1 AM (Life Technologies, Grand Island, NY) and imaged before and after $\mathrm{KCl}$ or Glu treatment. The images were captured every 3.95 seconds using timelapse settings, following an excitation with a 488 Argon laser. The average intensities of the Oregon Green 488 BAPTA-1 AM pre-loaded cells were measured using ImageJ $1.46 \mathrm{c}$ software. The fluorescence intensities of the cells recorded after the treatment were normalized to the pre-treatment ones, after background fluorescence subtraction.

\section{Immunocytochemistry}

Primary neurons were fixed in $4 \%$ PFA, permeabilized in $0.1 \%$ Tx-100 with $1.5 \%$ normal donkey serum (Jackson ImmunoResearch Labs, West Grove, PA), and incubated overnight at $4{ }^{\circ} \mathrm{C}$ with the following primary antibodies: goat anti-PS1 loop and mouse anti-Syt1 for the PS1-Syt1 proximity assay and rabbit anti-APP CT and mouse antiPS1 loop for the PS1-APP interaction assay. Corresponding Alexa Fluor 488- or Cy3-labeled secondary antibodies were added for 1 hour at room temperature before mounting the coverslips with VectaShield mounting medium (Vector Laboratories, Inc., Burlingame, CA).

\section{Fluorescent lifetime imaging microscopy (FLIM)}

The proximity between fluorophore labeled endogenous PS1 and Syt1, PS1 and APP, or PS1 NT and CT was evaluated by a previously validated FLIM assay $[22,56]$. Briefly, pulsing Chameleon Ti:Sapphire laser (Coherent Inc., Santa Clara, CA) was used to excite Alexa Fluor 488 donor fluorophore (two-photon excitation at $780 \mathrm{~nm}$ wavelength). The baseline lifetime ( $t 1)$ of the Alexa Fluor 488 fluorophore was measured in the absence of the Cy3 acceptor fluorophore (negative control, FRET absent). Donor fluorophore lifetimes were recorded using a high-speed photomultiplier tube (MCP R3809; Hamamatsu, Bridgewater, $\mathrm{NJ}$ ) and a fast time-correlated single-photon counting acquisition board (SPC-830; Becker \& Hickl, Berlin, Germany). In the presence of the acceptor fluorophore, excitation of the donor fluorophore yields reduced donor emission energy if the donor and the acceptor are less than 5-10 $\mathrm{nm}$ apart (FRET present). This results in a characteristic shortening of the donor fluorophore lifetime $(t 2)$. The acquired FLIM data were analyzed using SPC Image software (Becker \& 
Hickl, Berlin, Germany). The \% $\mathrm{E}_{\mathrm{FRET}}$ was calculated using the following equation: $\% \mathrm{E}_{\mathrm{FRET}}=100 *(t 1-t 2) / t 1$ [57]. The degree of the donor fluorophore lifetime shortening (or increase in the $\% \mathrm{E}_{\mathrm{FRET}}$ ) correlates with the increase in the proximity between the PS1 NT and CT, or PS1 and either Syt1 or APP molecules.

\section{Immunoelectron microscopy}

Adult CD1 mice were perfused with $4 \%$ paraformaldehyde (PFA) before the cortices were excised and $1 \mathrm{~mm}$ thick slices were fixed in a mixture of $0.1 \%$ tetroxide, dehydrated, and embedded in araldite/dodecynyl succinic anhydride (DDSA) resin (Electron Microscopy Sciences, Hatfield, PA). Then, $70 \mathrm{~nm}$-thick sections were cut on an ultracut microtome (Leica) and dried onto formar/carbon-coated mesh electron microscopy (EM) grids prior to immunostaining with anti-PS1 C-terminal fragment primary antibody (Sigma, P7854), followed by $6 \mathrm{~nm}-\mathrm{Ag}$-particles labeled secondary antibody (Aurion). Grids were negatively stained with $1 \%$ filtered uranyl acetate in $70 \%$ ethanol. The samples were examined and the images acquired using a JEOL $100 \mathrm{~S}$ electron microscope (JEOL, USA, Peabody MA).

\section{ELISA for $A \beta 40$ and $A \beta 42$}

To determine $A \beta$ levels secreted into conditioned medium, culture medium of each sample was replaced by an equal amount of serum-free Advanced DMEM supplemented with $2 \%$ GlutaMAX for PC12 cell lines and fresh Neurobasal growth medium supplemented with $2 \%$ GlutaMAX and $1 \%$ B27 for mouse primary neurons, respectively (Life Technologies, Grand Island, $N Y$ ). $A \beta 40$ and $A \beta 42$ levels were measured using hu$\mathrm{man} / \mathrm{rat} \mathrm{A} \beta 40$ and $A \beta 42$ enzyme-linked immunosorbent assay (ELISA) kits (Wako, Japan) according to the manufacturer's instructions. Each value recorded in ELISA was normalized to the protein concentration of the corresponding cell extract measured with a BCA protein assay (Pierce, Rockford, IL).

\section{Cell-free $\boldsymbol{\gamma}$-secretase assay}

The crude homogenates of cellular membranes were prepared from parental or Syt1 KD PC12 cells in $20 \mathrm{mM}$ HEPES ( $\mathrm{pH}$ 7.4) containing protease inhibitor cocktail (Roche, Indianapolis, IN). The lysates were centrifuged at 3000xg for 15 minutes to remove cellular debris and nuclei. The supernatant was collected and centrifuged further at 100,000xg for 1 hour in a L8-80 M ultracentrifuge equipped with a Ti70.1 rotor (Beckman). Equal amounts of $1 \%$ CHAPSO-solubilized membranes were incubated with C100-FLAG as a substrate (kindly provided by Dr. M.S. Wolfe, BWH, Boston, MA) for 4 hours at $37^{\circ} \mathrm{C}$. After the incubation, the samples were placed on ice to stop the reaction. For control purposes the reaction was carried out at $4{ }^{\circ} \mathrm{C}$ or in the presence of $\gamma$ secretase inhibitors.

\section{Fractionation of subcellular membrane vesicles by discontinuous OptiPrep density gradient}

Preparation of total cellular membranes and subcellular fractionation were based on procedures described previously [58] with minor modifications. In brief, parental or Syt1 KD PC12 cells grown to confluence were washed and harvested in cold HEPES buffer (25 mM HEPES, $150 \mathrm{mM} \mathrm{NaCl}, 1 \mathrm{mM}$ DTT, 2 mM EGTA, pH7.4). Cellular pellets were resuspended in the HEPES buffer and homogenized by passing through a 27 -gauge needle. Total cellular membranes isolated from parental or Syt1 KD PC12 cells were loaded on a step OptiPrep gradient of 10-30 \% with $2.5 \%$ increments and centrifuged in SW 41 Ti rotor (Beckman Coulter Life Sciences, Indianapolis, IN) at $100,000 \mathrm{xg}$ at $4{ }^{\circ} \mathrm{C}$ for 16 hours. Then, 13 fractions were collected from the bottom of each centrifuge tube by puncture and equal amounts of the fractions were subjected to SDS-PAGE and western blotting.

\section{Cell surface protein isolation}

Biotin-labeled cell surface proteins were isolated from parental and Syt1 KD PC12 cells using a Thermo Scientific $^{\text {Tu }}$ Pierce $^{\text {Tu }}$ Cell Surface Protein Isolation Kit (Pierce, Rockford, IL). Briefly, cells grown to confluence in collagen-coated dishes were incubated with sulfo-NHSSS-Biotin, dissolved in cold PBS, for 30 minutes at $4{ }^{\circ} \mathrm{C}$. After the incubation, the reaction was quenched by adding a quenching solution.

The cells were collected, washed twice with TBS, and lysed using a proprietary lysis reagent containing zwitterionic detergent in $25 \mathrm{nM}$ bicine buffer (pH7.6). The biotin-labeled protein was isolated with NeutrAvidin agarose by incubating the cell lysates with SDS-PAGE sample buffer (Pierce, Rockford, IL) containing 50 mM DTT. All the reagents, unless stated otherwise, were provided with the kit. Protein concentration in each sample was determined using BCA Protein Assay (Pierce, Rockford, IL) and equal amounts of protein were subjected to SDSPAGE and western blotting.

\section{Cycloheximide (CHX) pulse-chase assay}

Relative stability of the protein was estimated using a CHX pulse-chase assay. Parental and Syt1 KD PC12 cells were treated with $20 \mu \mathrm{g} / \mathrm{ml} \mathrm{CHX} \mathrm{(Sigma-Aldrich,}$ St. Louis, MO), diluted in the growth medium. The cells were collected in $0,2,4,8,24$, and 48 hours or 0 , $15,30,45$, and 90 minutes following the addition of CHX, and sonicated in $1 \% \mathrm{Tx}-100$ buffer (50 mM HEPES, $100 \mathrm{mM} \mathrm{NaCl}, \mathrm{pH} 7.4)$. The extracted proteins were analyzed by SDS-PAGE and western blotting. The intensity of 
each band was quantified using Image $1.46 \mathrm{c}$ software and normalized to the levels of a respective protein at 0 time point. The data were plotted on the graph, fitted with a one-phase decay curve, and analyzed with 2-way ANOVA followed by multiple comparison Bonferroni post-test, using GraphPad Prism 6 software.

\section{Notch1 processing assay}

Parental and Syt1 KD PC12 cells were transfected with construct encoding Myc-tagged Notch1 with deleted extracellular domain (N $\triangle E C D)$ or Myc-tagged Notch1 intracellular domain (NICD) as a control. To control for the specificity of the $\gamma$-secretase activity assay, the cells were treated for 12 hours with $500 \mathrm{nM} \gamma$-secretase inhibitor, $\mathrm{N}$-[N-(3,5-difluorophenacetyl)-L-alanyl]-S-phenylglycine t-butyl ester (DAPT), or DMSO added to the medium 12 hours after the transfection. Total protein was extracted from the cells, resolved by SDS-PAGE, and N $\triangle E C D$ and NICD were detected using anti-Myc antibody (Pierce, Rockford, IL). The intensities of the bands corresponding to $\mathrm{N} \triangle \mathrm{ECD}$ and NICD were quantified using ImageJ 1.46c software, and the NICD/N $\triangle E C D$ ratio was compared between parental and Syt1 KD cells.

\section{Statistics}

To determine whether the $R / G$ ratio in neurons treated with either $\mathrm{KCl}$ or glutamate differs from the one in cells treated with the vehicle control, a mixed model for the log ratio with repeated measures and random effects was constructed and tested. Fixed effects were treatment, pre- vs. post-treatment indicator, and the interaction between them. Repeated measures over time employed a covariance structure of first order auto-regressive moving average (ARMA $(1,1))$. To allow for different baseline levels for individual neurons, a random intercept was included in the model. To answer the question whether the increased R/G ratio in the cells treated with Glu actually goes back to the baseline, we fitted a piecewise mixed linear model for the treated group. This model includes linear components broken down by the time interval points 0 to 5 (before treatment), 5 to 6 (immediately after treatment) and 6 on as fixed effects and random effects to allow different slopes for individual cells and repeated measures with autoregressive covariance structure. In order to test a decrease in the ratio back to pre-treatment levels, piecewise time components were designed to test a non-zero slope. The results from the model suggest a slope that is significantly different from 0 for the interval point 5 to 6 ( $p$-value 0.0001 ). The parameter estimate for this slope is positive, which is in line with the hypothesized increase in the R/G ratio between the time of treatment initiation and the time point 6 . The slope for the time interval point 6 on is also significantly different from 0 ( $p$-value 0.024$)$ with a negative parameter estimate, suggesting again the hypothesized decrease in $\mathrm{R} / \mathrm{G}$ ratio. In addition, the initial time interval in the model, which corresponds with the baseline pretreatment period, does not present with a slope significantly different than 0 , suggesting no trend in the ratio, which is an expected outcome under no activity.

Statistical analysis of the FLIM data was performed using StatView for Windows, Version 5.0.1 (SAS Institute, Inc.). For quantitative western blotting, the intensities of the bands corresponding to target proteins were measured using ImageJ 1.46c software and compared between the samples. Statistics were calculated with Microsoft Office Excel 2007 or GraphPad $^{\oplus}$ Prism 6 software using a twotailed unpaired student-test, Mann-Whitney's $U$ test or 2-way ANOVA with Bonferroni multiple comparison post-test. $P$-value of $<0.05$ was a predetermined threshold for statistical significance. The data were recorded from at least three different samples obtained on separate days; $\mathrm{n}$ indicates biological replicates for each experiment.

\section{Ethics approval}

All experiments involving use of the mouse brain tissue were approved by the Subcommittee for Research Animal Care at the Massachusetts General Hospital.

\section{Availability of supporting data}

The datasets supporting the conclusions of this article are available in the IMEx consortium - IntAct $[\mathrm{X}]$ repository [IM-25035] and included in the article as additional files. Additional file 7 presents individual values recorded in the experiments where $\mathrm{n}<6$. (XLSX $270 \mathrm{~kb}$ )

\section{Additional files}

Additional file 1: Spectral FRET analysis of the GFP and RFP intensities Primary neurons were transfected with GFP-PS1 (negative FRET control, $n=12$ cells), RFP-GFP fusion (R-G, positive FRET control, $n=24$ ) or GFPPS1-RFP (PS1 conformation FRET probe, $n=10$ ). The GFP was excited by argon laser at $488 \mathrm{~nm}$ wavelength, and the emission intensities of GFP and RFP within the $513 \pm 10.57 \mathrm{~nm}$ and $598 \pm 10.57 \mathrm{~nm}$ spectral bandwidth of the Metadector, respectively, were collected every 3 minutes for the duration of 33 minutes (middle and bottom graphs, respectively). The arrow indicates the time point of $50 \mathrm{mM} \mathrm{KCl}$ stimulation. No significant change in the GFP or RFP fluorescence emission intensity (no photobleaching), or the R/G ratio was observed in the G-PS1 and R-G transfected cells. The change in the R/G ratio after $\mathrm{KCl}$ stimulation was detected only in G-PS1-R transfected cells due to increased FRET efficiency/change in PS1 conformation. The black line shows mean \pm SEM values. (TIF $1663 \mathrm{~kb}$ )

Additional file 2: Proteins identified in mass spectrometry screen of mouse brain lysates for novel PS1 calcium-dependent interactors. Synaptotagmin 1 (Syt1) was detected in high calcium condition (calcium +) when GST-PS1 L6-7 and GST-PS1 NT recombinant peptides were used for pull-down. Excised band size and protein matches are indicated. ( $n=3$; Data from one representative experiment is shown). (XLSX $20 \mathrm{~kb}$ )

Additional file 3: Knock-down and overexpression of Syt1 in PC12 cells. Representative western blot demonstrates successful stable RNAi-mediated knock-down of endogenous Syt1 and huSyt1-V5 overexpression in PC12 cell line. The graph shows quantitative analysis of the rat and rat + human Syt1 levels. Data are presented as mean \pm SEM, $n=3$ for Syt $1 \mathrm{KD}+$ Syt $1-\mathrm{V} 5$ and for 
parental PC12; and $n=4$ for other conditions. Statistical significance was determined using unpaired student $t$-test; ${ }^{*} p<0.05,{ }^{* *} p<0.01$. (TIF $1863 \mathrm{~kb}$ )

Additional file 4: PS1 and APP stability is not affected by Syt1 KD. A, Parental and Syt1 KD PC12 cells were treated with cycloheximide and harvested $0,2,4,8,24$, and 48 hours after the treatment. Western blot presents degradation of PS1 over time. Anti-PS1 C-terminal antibody was used for detection. The quantitative analysis of PS1 levels reveals no difference in the half-life of PS1 in Syt1 KD PC12 cells compared to the parental control. Statistical significance was determined using 2-way ANOVA with Bonferroni post-test, $n=5$. B, Parental and Syt1 KD PC12 cells were treated with cycloheximide and harvested $0,15,30$, 45, and 90 minutes after the treatment. Western blot presents the level of APP over time. Anti-APP C-terminal antibody was used for detection. The quantitative analysis of APP levels revealed no difference in the half-life of APP in Syt1 KD PC12 cells compared to the parental control. Statistical significance was determined using 2-way ANOVA with Bonferroni post-test, $n=3$. (TIF $3814 \mathrm{~kb}$ )

Additional file 5: Overall transport fidelity is not altered by Syt1 KD. A Western blots show distribution of Nct and Pen-2 in 13 subcellular fractions from parental and Syt1 KD cells. No differences in the subcellular distribution of Nct and Pen-2 were observed between parental and Syt1 KD cells. The enrichment of the respective subcellular compartments was determined by western blotting with anti-calreticulin, anti-GM130, anti-Tgn46, and antiRab11 antibodies. The fractions that correspond to the respective intracellular compartments are indicated above the western blots. B, Western blots show distribution of organelle (GM130, Tgn46, calreticulin, and Rab11) and synaptic vesicle marker, synaptophysin, in 13 subcellular fractions from parental and Syt1 KD cells. No significant differences in the subcellular distribution of organelles and synaptophysin (Syp) between parental and Syt1 KD cells were observed. (TIF $3749 \mathrm{~kb}$ )

Additional file 6: Syt1 is not a substrate for $\gamma$-secretase. A, B, Western blots show levels of mature, immature, nascent Syt1, and Syt1 C-terminal fragments (Syt1 CTF) in mouse primary neurons (A) and PS-/- mouse embryonic fibroblasts (MEF) transfected with huSyt1-V5 and PS1 (as indicated) (B). Inhibition of the $\gamma$-secretase activity with DAPT and L685,458 did not alter Syt1 processing. GFP (transfection efficiency) and $\beta$ actin (loading) are shown as controls. (TIF $1352 \mathrm{~kb}$ )

Additional file 7: Supporting data values. The file presents individual values recorded in the experiments where $n<6$. (XLSX $270 \mathrm{~kb})$

\section{Abbreviations}

AD: Alzheimer's disease; AICD: Amyloid intracellular domain; APP: Amyloid precursor protein; $A \beta$ : Amyloid $\beta$; BACE1: $\beta$-secretase; $\mathrm{CHO}$ : Chinese hamster ovary cell line; $C H X$ : Cycloheximide - inhibitor of protein biosynthesis; $C T$ : Cterminus; CTF: C-terminal fragment; DAPT: N-[N-(3,5-Difluorophenacetyl)-Lalanyl]-S-phenylglycine t-butyl ester - $\gamma$-secretase inhibitor; DIV: Days in vitro; fAD: Familial Alzheimer's disease; FL: Full length; FLIM: Fluorescence lifetime imaging microscopy; FRET: Förster Resonance Energy Transfer; G-PS1-R: GFPPS1-RFP - PS1 tagged with green fluorescent protein at the $\mathrm{N}$-terminus and RFP within the loop domain; GST: Glutathione S-transferase; KD: Knock-down; MEF: Mouse embryonic fibroblasts; MS: Mass spectrometry; NICD: Notch 1 intracellular domain; NT: N-terminus; NTF: N-terminal fragment; NAECD: Notch1 with deleted extracellular domain; PC12: Rat pheochromocytoma cell line; PS1: Presenilin 1; PS1 L6-7: Loop domain between 6th and 7th transmembrane helices of PS1; R-G: Fusion of red and green fluorescent proteins; sAPPa/ B: Secreted amyloid precursor protein a/B; SNS: Synaptoneurosomes; SV: Synaptic vesicles; Syt1: Synaptotagmin 1; wt: Wild type.

\section{Competing interests}

The authors declare that they have no competing interests.

\section{Authors' contributions}

AK and KMZ designed, performed, and analyzed the biochemical experiments. KP, MA, and SS performed and analyzed the FLIM experiments. XL performed and analyzed spectral FRET/time-lapse and GST-pull down experiments; AM did statistical analysis. DK and VG provided reagents and discussed the data. MM and BTH discussed the data. OB conceived of the study, and participated in its design and coordination. $\mathrm{AK}, \mathrm{KMZ}$ and $\mathrm{OB}$ wrote the manuscript. All authors read and approved the final manuscript.

\section{Acknowledgements}

We thank Zhanyun Fan (MGH, Boston) for help with generating Syt1 calcium mutant constructs and Dr. A.B.Harkins (St. Louis University School of Medicine) for PC12 parental and Syt1 KD cell lines. This work was supported by NIH grants AG15379 and AG044486 (OB) and 'The Kyoto University Foundation' (AK).

\section{Author details}

${ }^{1}$ MassGeneral Institute for Neurodegenerative Disease, Department of Neurology, Massachusetts General Hospital, Harvard Medical School, Charlestown, MA 02129, USA. ${ }^{2}$ MGH Biostatistics Center, Massachusetts General Hospital, Boston, MA 02114, USA.

Received: 4 February 2016 Accepted: 18 March 2016 Published online: 31 March 2016

\section{References}

1. De Strooper B, Saftig P, Craessaerts K, Vanderstichele H, Guhde G, Annaert W, et al. Deficiency of presenilin-1 inhibits the normal cleavage of amyloid precursor protein. Nature. 1998;391(6665):387-90.

2. Wolfe MS, Xia W, Ostaszewski BL, Diehl TS, Kimberly WT, Selkoe DJ. Two transmembrane aspartates in presenilin-1 required for presenilin endoproteolysis and gamma-secretase activity. Nature. 1999:398(6727):513-7.

3. Vassar R, Bennett BD, Babu-Khan S, Kahn S, Mendiaz EA, Denis P, et al. Betasecretase cleavage of Alzheimer's amyloid precursor protein by the transmembrane aspartic protease BACE. Science. 1999;286(5440):735-41.

4. Querfurth HW, LaFerla FM. Alzheimer's disease. N Engl J Med. 2010;362(4): 329-44.

5. Mucke L, Selkoe DJ. Neurotoxicity of amyloid beta-protein: synaptic and network dysfunction. Cold Spring Harb Perspect Med. 2012;2(7):a006338.

6. Jack Jr CR, Lowe VJ, Weigand SD, Wiste HJ, Senjem ML, Knopman DS, et al. Serial PIB and MRI in normal, mild cognitive impairment and Alzheimer's disease: implications for sequence of pathological events in Alzheimer's disease. Brain. 2009:132(Pt 5):1355-65.

7. Terry RD, Masliah E, Salmon DP, Butters N, DeTeresa R, Hill R, et al. Physical basis of cognitive alterations in Alzheimer's disease: synapse loss is the major correlate of cognitive impairment. Ann Neurol. 1991;30(4):572-80.

8. Knobloch M, Mansuy IM. Dendritic spine loss and synaptic alterations in Alzheimer's disease. Mol Neurobiol. 2008;37(1):73-82.

9. Marcello E, Epis R, Di Luca M. Amyloid flirting with synaptic failure: towards a comprehensive view of Alzheimer's disease pathogenesis. Eur J Pharmacol. 2008:585(1):109-18.

10. Kikuchi M, Hirosawa T, Yokokura M, Yagi S, Mori N, Yoshikawa E, et al. Effects of brain amyloid deposition and reduced glucose metabolism on the default mode of brain function in normal aging. J Neurosci. 2011;31(31):11193-9.

11. Kamenetz F, Tomita T, Hsieh H, Seabrook G, Borchelt D, Iwatsubo T, et al. APP processing and synaptic function. Neuron. 2003:37(6):925-37.

12. Bero AW, Yan P, Roh JH, Cirrito JR, Stewart FR, Raichle ME, et al. Neuronal activity regulates the regional vulnerability to amyloid-beta deposition. Nat Neurosci. 2011;14(6):750-6

13. Li X, Uemura K, Hashimoto T, Nasser-Ghodsi N, Arimon M, Lill CM, et al. Neuronal activity and secreted amyloid beta lead to altered amyloid beta precursor protein and presenilin 1 interactions. Neurobiol Dis. 2013;50:127-34.

14. Cirrito JR, Yamada KA, Finn MB, Sloviter RS, Bales KR, May PC, et al. Synaptic activity regulates interstitial fluid amyloid-beta levels in vivo. Neuron. 2005; 48(6):913-22.

15. Brose N, Petrenko AG, Sudhof TC, Jahn R. Synaptotagmin: a calcium sensor on the synaptic vesicle surface. Science. 1992;256(5059):1021-5.

16. Xu J, Pang ZP, Shin OH, Sudhof TC. Synaptotagmin-1 functions as a Ca2+ sensor for spontaneous release. Nat Neurosci. 2009;12(6):759-66.

17. Stevens CF, Sullivan JM. The synaptotagmin C2A domain is part of the calcium sensor controlling fast synaptic transmission. Neuron. 2003;39(2):299-308.

18. Sudhof TC. Calcium control of neurotransmitter release. Cold Spring Harb Perspect Biol. 2012:4(1):a011353.

19. Querfurth HW, Selkoe DJ. Calcium ionophore increases amyloid beta peptide production by cultured cells. Biochemistry. 1994;33(15):4550-61.

20. Pierrot N, Ghisdal P, Caumont AS, Octave JN. Intraneuronal amyloid-beta142 production triggered by sustained increase of cytosolic calcium concentration induces neuronal death. J Neurochem. 2004;88(5):1140-50.

21. Kim SH, Fraser PE, Westaway D, St George-Hyslop PH, Ehrlich ME, Gandy S. Group II metabotropic glutamate receptor stimulation triggers production 
and release of Alzheimer's amyloid(beta) 42 from isolated intact nerve terminals. J Neurosci. 2010;30(11):3870-5.

22. Lleo A, Berezovska O, Herl L, Raju S, Deng A, Bacskai BJ, et al. Nonsteroidal anti-inflammatory drugs lower Abeta(42) and change presenilin 1 conformation. Nat Med. 2004;10(10):1065-6.

23. Berezovska O, Lleo A, Herl LD, Frosch MP, Stern EA, Bacskai BJ, et al. Familial Alzheimer's disease presenilin 1 mutations cause alterations in the conformation of presenilin and interactions with amyloid precursor protein. J Neurosci. 2005;25(11):3009-17.

24. Isoo N, Sato C, Miyashita H, Shinohara M, Takasugi N, Morohashi Y, et al. Abeta42 overproduction associated with structural changes in the catalytic pore of gamma-secretase: common effects of pen-2 N-terminal elongation and fenofibrate. J Biol Chem. 2007;282(17):12388-96.

25. Uemura K, Lill CM, Li X, Peters JA, Ivanov A, Fan Z, et al. Allosteric modulation of PS1/gamma-secretase conformation correlates with amyloid beta(42/40) ratio. PLoS One. 2009;4(11):e7893.

26. Fraering PC, LaVoie MJ, Ye W, Ostaszewski BL, Kimberly WT, Selkoe DJ, et al. Detergent-dependent dissociation of active gamma-secretase reveals an interaction between Pen-2 and PS1-NTF and offers a model for subunit organization within the complex. Biochemistry. 2004;43(2):323-33.

27. Shao X, Davletov BA, Sutton RB, Sudhof TC, Rizo J. Bipartite Ca2 +-binding motif in C2 domains of synaptotagmin and protein kinase C. Science. 1996;273(5272):248-51.

28. Fukumori A, Fluhrer $R$, Steiner $H$, Haass $C$. Three-amino acid spacing of presenilin endoproteolysis suggests a general stepwise cleavage of gamma-secretasemediated intramembrane proteolysis. J Neurosci. 2010;30(23):7853-62.

29. Qi-Takahara Y, Morishima-Kawashima M, Tanimura Y, Dolios G, Hirotani N, Horikoshi $Y$, et al. Longer forms of amyloid beta protein: implications for the mechanism of intramembrane cleavage by gamma-secretase. J Neurosci. 2005;25(2):436-45.

30. Zhang C, Wu B, Beglopoulos V, Wines-Samuelson M, Zhang D, Dragatsis I, et al. Presenilins are essential for regulating neurotransmitter release. Nature. 2009;460(7255):632-6.

31. Cirrito JR, Kang JE, Lee J, Stewart FR, Verges DK, Silverio LM, et al. Endocytosis is required for synaptic activity-dependent release of amyloid-beta in vivo. Neuron. 2008;58(1):42-51.

32. Takahashi RH, Milner TA, Li F, Nam EE, Edgar MA, Yamaguchi $H$, et al. Intraneuronal Alzheimer abeta42 accumulates in multivesicular bodies and is associated with synaptic pathology. Am J Pathol. 2002;161(5):1869-79.

33. Koffie RM, Meyer-Luehmann M, Hashimoto T, Adams KW, Mielke ML, GarciaAlloza M, et al. Oligomeric amyloid beta associates with postsynaptic densities and correlates with excitatory synapse loss near senile plaques. Proc Natl Acad Sci U S A. 2009:106(10):4012-7.

34. Kuperstein I, Broersen K, Benilova I, Rozenski J, Jonckheere W, Debulpaep M, et al. Neurotoxicity of Alzheimer's disease Abeta peptides is induced by small changes in the Abeta42 to Abeta40 ratio. EMBO J. 2010;29(19):3408-20.

35. Borchelt DR, Thinakaran G, Eckman CB, Lee MK, Davenport F, Ratovitsky T, et al. Familial Alzheimer's disease-linked presenilin 1 variants elevate Abeta142/1-40 ratio in vitro and in vivo. Neuron. 1996;17(5):1005-13.

36. Scheuner D, Eckman C, Jensen M, Song X, Citron M, Suzuki N, et al. Secreted amyloid beta-protein similar to that in the senile plaques of Alzheimer's disease is increased in vivo by the presenilin 1 and 2 and APP mutations linked to familial Alzheimer's disease. Nat Med. 1996;2(8):864-70.

37. De Strooper B. Loss-of-function presenilin mutations in Alzheimer disease. Talking point on the role of presenilin mutations in Alzheimer disease. EMBO Rep. 2007;8(2):141-6.

38. Serneels L, Van Biervliet J, Craessaerts K, Dejaegere T, Horre K, Van Houtvin $T$, et al. gamma-Secretase heterogeneity in the Aph1 subunit: relevance for Alzheimer's disease. Science. 2009;324(5927):639-42.

39. Wahlster L, Arimon M, Nasser-Ghodsi N, Post KL, Serrano-Pozo A, Uemura K, et al. Presenilin-1 adopts pathogenic conformation in normal aging and in sporadic Alzheimer's disease. Acta Neuropathol. 2013;125(2):187-99.

40. Dolev I, Fogel H, Milshtein H, Berdichevsky Y, Lipstein N, Brose N, et al. Spike bursts increase amyloid-beta 40/42 ratio by inducing a presenilin-1 conformational change. Nat Neurosci. 2013;16(5):587-95.

41. Gautam V, D'Avanzo C, Berezovska O, Tanzi RE, Kovacs DM. Synaptotagmins interact with APP and promote Abeta generation. Mol Neurodegener. 2015;10:31.

42. Chavez-Gutierrez L, Bammens L, Benilova I, Vandersteen A, Benurwar M, Borgers $\mathrm{M}$, et al. The mechanism of $\gamma$-Secretase dysfunction in familial Alzheimer disease. EMBO J. 2012;31(10):2261-74.
43. Frykman S, Hur JY, Franberg J, Aoki M, Winblad B, Nahalkova J, et al. Synaptic and endosomal localization of active gamma-secretase in rat brain. PLoS One. 2010;5(1):e8948.

44. Groemer TW, Thiel CS, Holt M, Riedel D, Hua Y, Huve J, et al. Amyloid precursor protein is trafficked and secreted via synaptic vesicles. PLoS One. 2011;6(4):e18754.

45. Kandalepas PC, Sadleir KR, Eimer WA, Zhao J, Nicholson DA, Vassar R. The Alzheimer's beta-secretase BACE1 localizes to normal presynaptic terminals and to dystrophic presynaptic terminals surrounding amyloid plaques. Acta Neuropathol. 2013;126(3):329-52.

46. Del Prete D, Lombino F, Liu X, D'Adamio L. APP is cleaved by Bace1 in pre-synaptic vesicles and establishes a pre-synaptic interactome, via its intracellular domain, with molecular complexes that regulate pre-synaptic vesicles functions. PLoS One. 2014;9(9):e108576.

47. Das U, Wang L, Ganguly A, Saikia JM, Wagner SL, Koo EH, et al. Visualizing APP and BACE-1 approximation in neurons yields insight into the amyloidogenic pathway. Nat Neurosci. 2016;19(1):55-64.

48. Kohli BM, Pflieger D, Mueller LN, Carbonetti G, Aebersold R, Nitsch RM, et al. Interactome of the amyloid precursor protein APP in brain reveals a protein network involved in synaptic vesicle turnover and a close association with Synaptotagmin-1. J Proteome Res. 2012;11(8):4075-90.

49. Sannerud R, Declerck I, Peric A, Raemaekers T, Menendez G, Zhou L, et al. ADP ribosylation factor 6 (ARF6) controls amyloid precursor protein (APP) processing by mediating the endosomal sorting of BACE1. Proc Natl Acad Sci U S A. 2011;108(34):E559-68.

50. Burgos PV, Mardones GA, Rojas AL, da Silva LL, Prabhu Y, Hurley JH, et al. Sorting of the Alzheimer's disease amyloid precursor protein mediated by the AP-4 complex. Dev Cell. 2010;18(3):425-36.

51. Perez RG, Soriano S, Hayes JD, Ostaszewski B, Xia W, Selkoe DJ, et al. Mutagenesis identifies new signals for beta-amyloid precursor protein endocytosis, turnover, and the generation of secreted fragments, including Abeta42. J Biol Chem. 1999;274(27):18851-6.

52. Kuzuya A, Uemura K, Kitagawa N, Aoyagi N, Kihara T, Ninomiya H, et al. Presenilin 1 is involved in the maturation of beta-site amyloid precursor protein-cleaving enzyme 1 (BACE1). J Neurosci Res. 2007;85(1):153-65.

53. Einarson MB, Pugacheva EN, Orlinick JR. Preparation of GST fusion proteins. CSH Protoc. 2007:2007:Pdb.prot4738.

54. Hollingsworth EB, MCNeal ET, Burton JL, Williams RJ, Daly JW, Creveling CR. Biochemical characterization of a filtered synaptoneurosome preparation from guinea pig cerebral cortex: cyclic adenosine 3':5'-monophosphategenerating systems, receptors, and enzymes. J Neurosci. 1985;5(8):2240-53.

55. Moore JM, Papke JB, Cahill AL, Harkins AB. Stable gene silencing of synaptotagmin I in rat PC12 cells inhibits Ca2+-evoked release of catecholamine. Am J Physiol Cell Physiol. 2006;291(2):C270-81.

56. Berezovska O, Bacskai BJ, Hyman BT. Monitoring proteins in intact cells. Sci Aging Knowledge Environ. 2003;2003(23):E14

57. Lakowicz JR, Szmacinski H, Nowaczyk K, Berndt KW, Johnson M. Fluorescence lifetime imaging. Anal Biochem. 1992;202(2):316-30.

58. Li X, Donowitz M. Fractionation of subcellular membrane vesicles of epithelial and nonepithelial cells by OptiPrep density gradient ultracentrifugation. Methods Mol Biol. 2008;440:97-110.

\section{Submit your next manuscript to BioMed Central and we will help you at every step:}

- We accept pre-submission inquiries

- Our selector tool helps you to find the most relevant journal

- We provide round the clock customer support

- Convenient online submission

- Thorough peer review

- Inclusion in PubMed and all major indexing services

- Maximum visibility for your research

Submit your manuscript at www.biomedcentral.com/submit 